\title{
Thermal Pollution Mitigation in Cold Water Stream Watersheds Using Bioretention
}

\author{
Daniel Lewis Long \\ Thesis submitted to the faculty of the \\ Virginia Polytechnic Institute and State University \\ in partial fulfillment of the requirements for the degree of \\ Master of Science \\ in \\ Environmental Engineering
}

Randel L. Dymond

Erich T. Hester

Kevin D. Young

February $4^{\text {th }}, 2011$

Blacksburg, Virginia

Keywords: Stormwater Management, Low Impact Development, BMPs, Hydrology 


\title{
Thermal Pollution Mitigation in Cold Water Stream Watersheds Using Bioretention
}

\author{
Daniel Lewis Long
}

ABSTRACT

This study examines the use of bioretention as a strategy to reduce the thermal impact associated with urban stormwater runoff in developing cold water stream watersheds. Temperature and flow data were collected during ten controlled trials at a bioretention facility located in Blacksburg, Virginia. It was determined that bioretention has the ability to reduce the temperature of thermally charged stormwater runoff received from an asphalt surface. Significant reductions in average and peak temperatures were observed. However, this facility was unable to consistently reduce the temperature below the threshold for trout health. The ability of bioretention to reduce runoff flow rates could also serve to reduce the thermal impact. Based on these results it was concluded that bioretention appears to have the capability to reduce the thermal impact of urban stormwater runoff on cold water stream ecosystems. 


\section{Acknowledgments}

I would like to begin by expressing my appreciation to my advisor, Dr. Randy Dymond, for giving me this great opportunity. His encouragement made it possible to build upon my Forestry background and transition into a student of the Engineering discipline. I would also like to thank Dr. Erich Hester and Kevin Young for offering their time and expertise while serving on my committee. The Town of Blacksburg Public Works Department, the Blacksburg Fire Department, and town engineer Lee Hixon all provided assistance in my research endeavors. I am grateful to my Alma Mater, The Pennsylvania State University, for molding me and providing me with auspicious connections. Lastly, I could not have completed this program without the enduring support of all my family and friends. My success is as much a testament to those that are close to me as it is to my own abilities. Emulating my family members and summers spent at the sawmill have instilled in me the character that made it possible to achieve this goal. 


\section{Contents}

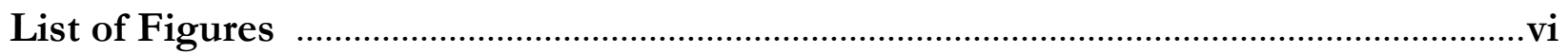

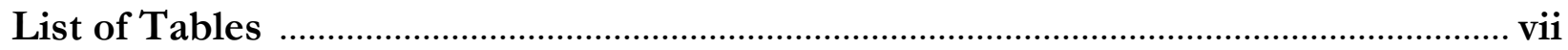

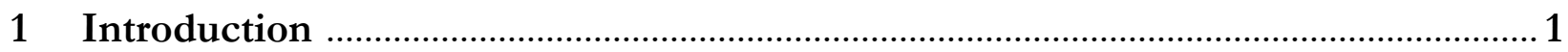

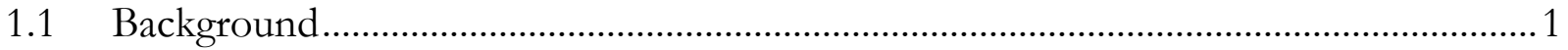

1.2 Problem Statement .......................................................................................

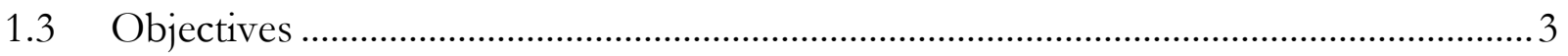

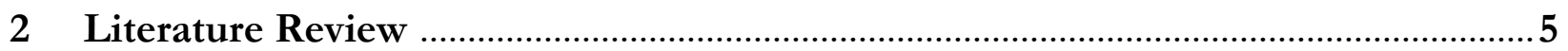

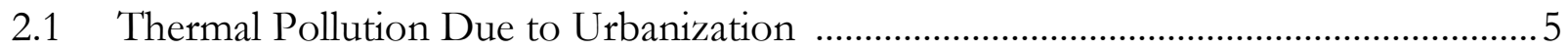

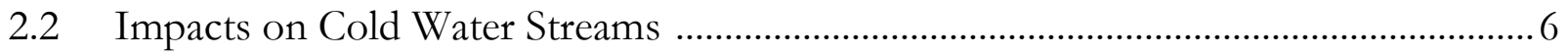

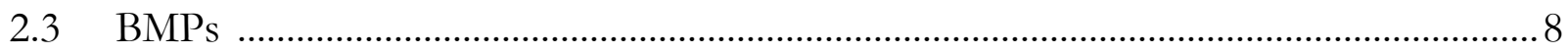

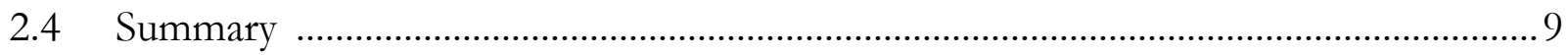

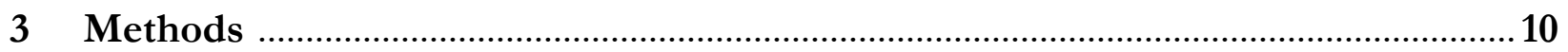

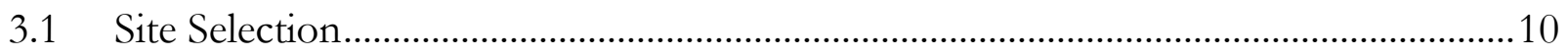

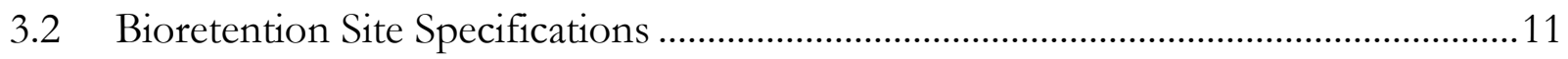

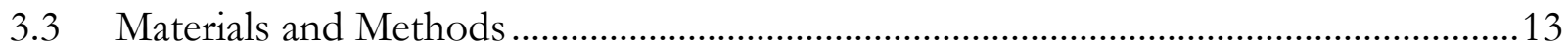

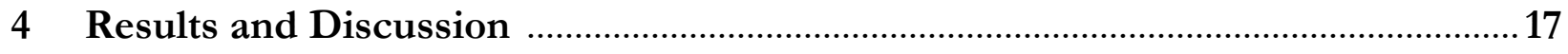




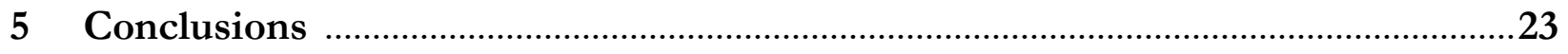

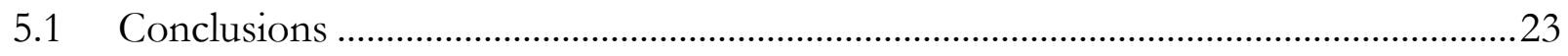

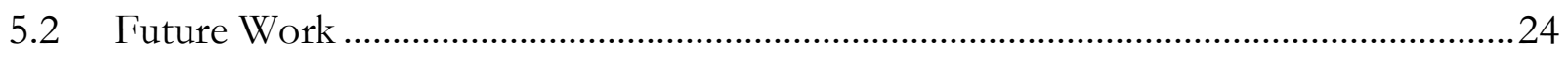

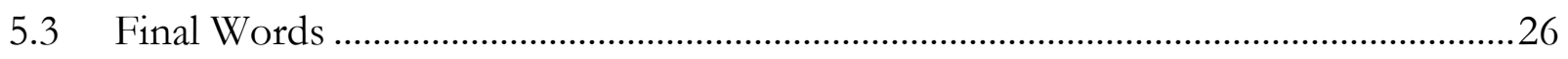

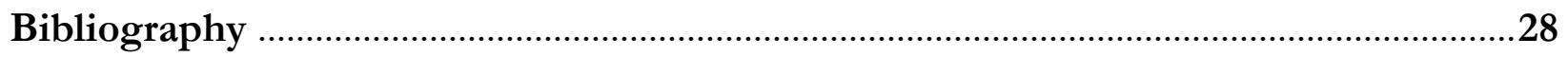

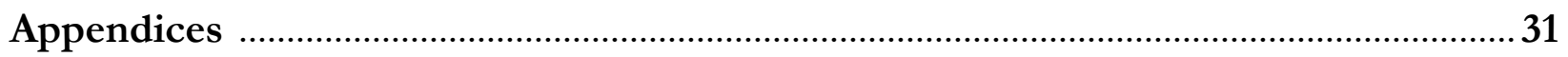

Appendix A: Temperature and Flow Data................................................................. 31 


\section{List of Figures}

3.1 Aerial Image of Bioretention Facility and Treated Area .................................................12

3.2 Community Center Bioretention Facility ………………………………………….....

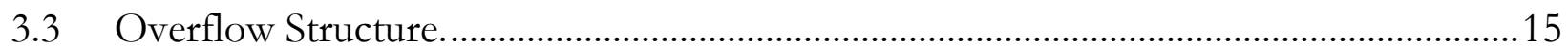

3.4 Inlet to Bioretention Facility ......................................................................................16

3.5 Outfall to Dry Detention Pond ……………………...................................................16

4.1 Peak and average temperatures for each trial .................................................................19

4.2 Temperature increase across the parking lot versus the air temperature .........................20

4.3 Temperature decrease through bioretention versus the air temperature .........................20

4.4 Thermal reduction through bioretention versus the volume of runoff treated ..............21

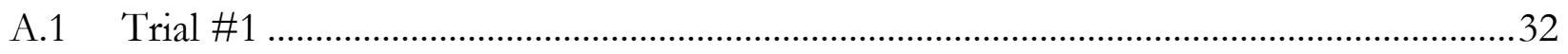

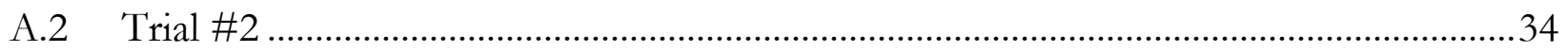

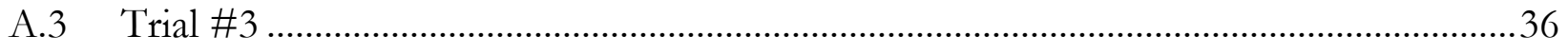

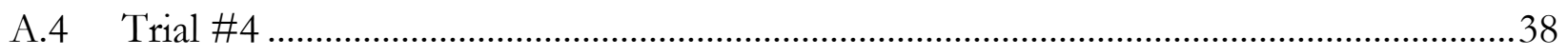

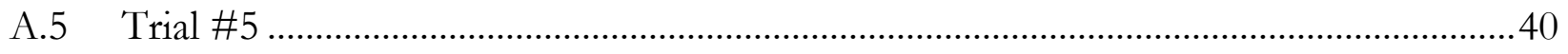

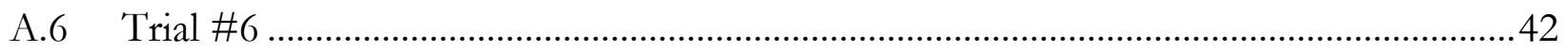

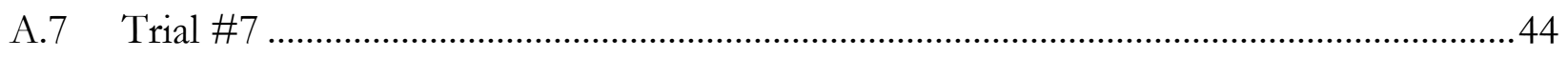

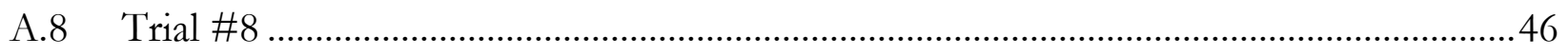

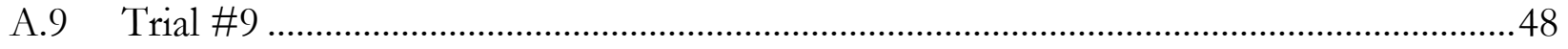

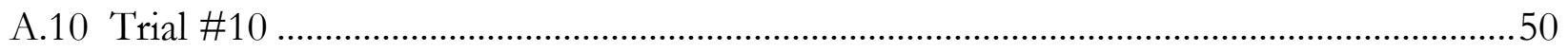




\section{List of Tables}

2.1 Numerical criteria for dissolved oxygen, $\mathrm{pH}$, and maximum temperature ....................

4.1 Summary statistics for runoff temperatures................................................................

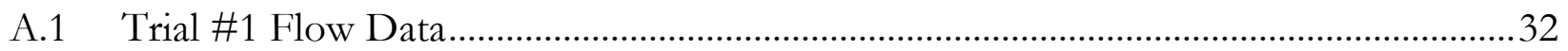

A.2 Trial \#1 Temperature Data ..........................................................................................

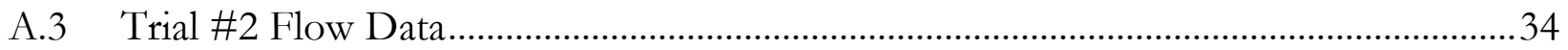

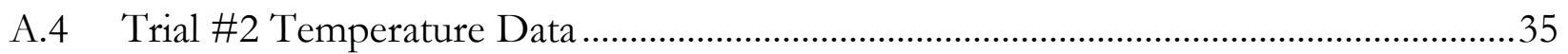

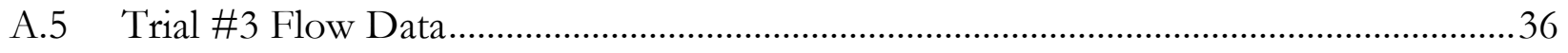

A.6 Trial \#3 Temperature Data ..................................................................................................

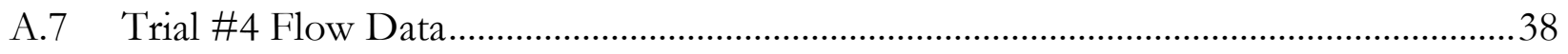

A.8 Trial \#4 Temperature Data ...........................................................................................

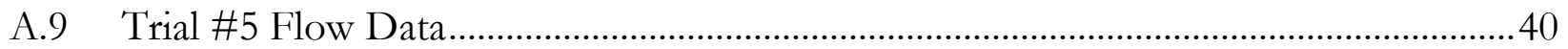

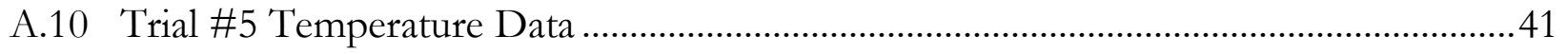

A.11 Trial \#6 Flow Data ...................................................................................................

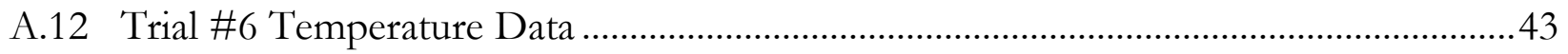

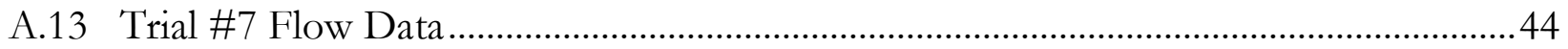

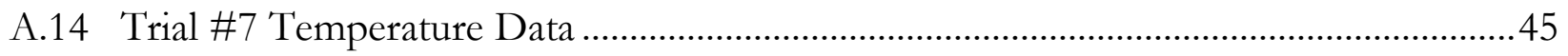

A.15 Trial \#8 Flow Data .............................................................................................................

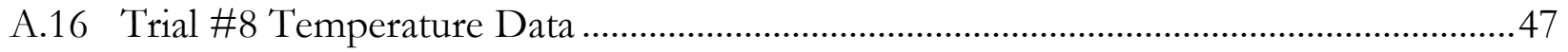

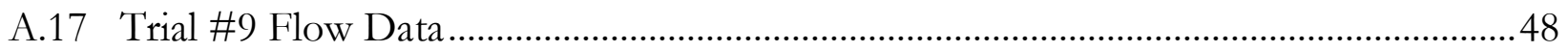




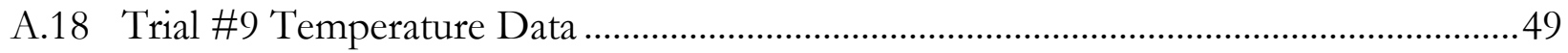

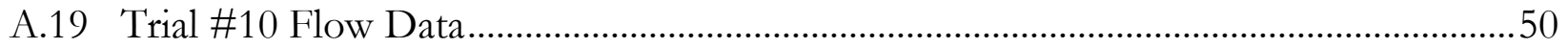

A.20 Trial \#10 Temperature Data .............................................................................................51 


\section{Chapter 1}

\section{Introduction}

\subsection{Background}

Land development is known to alter the natural hydrologic state of a watershed. As the area of impervious surface in a watershed increases, the result is larger peak flows, greater runoff volumes, and shorter lag times. Water quality is diminished as more pollutants are released into the waters of developed watersheds. The associated downstream effects include flooding, erosion, and increased sediment, nutrient, and pollutant loads. Traditional stormwater management practices were designed to maintain the pre-development peak flows. In recent years, best management practices (BMPs) have attempted to mimic all aspects of the pre-development hydrology of a site. The practice of maintaining the natural hydrologic characteristics of the site is part of the field referred to as low impact development (LID). Many studies have evaluated the water quantity and quality benefits of BMPs, however, only recently have the thermal remediation effects been considered.

During a rain event, stormwater flows as sheet flow across impervious surfaces. Sheet flow allows for accelerated heat energy transfer between the runoff and the impervious surface. Asphalt in particular, when heated by solar radiation, becomes very hot and can transfer significant heat energy to runoff. This is most evident during summer months when brief late afternoon thunderstorms occur at the end of hot sunny days. Runoff shows an initial temperature spike, with temperatures decreasing as the storm progresses. Often this heated runoff enters the stormwater system and is released directly to a stream. The temperature spike associated with these events has the potential to cause significant heat damage to cold water stream ecosystems.

Water temperature is an important aspect of water quality in many portions of the country. It is often neglected when designing BMPs to maintain pre-development conditions. 
Temperature is listed as a pollutant in the Clean Water Act and is commonly regulated in point-source discharges. However, as with most pollutants, temperature is difficult to control when originating from non-point sources. Total maximum daily load (TMDL) programs for thermal pollution are largely unsuccessful when implemented for streams due to the natural variability of water temperatures. One of the major non-point sources of thermal pollution is stormwater runoff from impervious surfaces in urbanized watersheds. This heated runoff is released into cold water streams where the heat flux can harm or kill many aquatic organisms. Dissolved oxygen levels in a stream are inversely related to the water temperature. Cold water dependent species such as trout are adapted to the cool temperatures maintained in canopy covered groundwater fed mountain streams. These sensitive ecosystems are often drastically altered or destroyed when traditional development occurs within a cold water stream watershed.

Bioretention, also referred to as rain gardens, is a popular BMP that is proven to reduce runoff and improve water quality. It employs plants, soils, and microbes to treat stormwater runoff using biological, chemical, and physical processes. Bioretention typically consists of a shallow vegetated depression that receives stormwater runoff from a site. Underneath is an engineered soil media that is designed to filter runoff at a specified rate. A variety of hearty grasses, shrubs, and small trees are generally planted in the soil media. Bioretention is divided into two primary categories: infiltration and filtration. An infiltration bioretention facility is designed so the stormwater runoff that is not treated through evapotranspiration or sorption is infiltrated to groundwater. Many areas have soils that do not allow an infiltration rate sufficient to handle most events. In these areas filtration bioretention facilities are used. A filtration facility contains an underdrain, which is a perforated pipe that captures the runoff after it has filtered through the soil media and releases it to the stormwater system. The media is designed to temporarily retain a certain amount of runoff so that it can be evapotranspirated and therefore never contribute to runoff from the site. Microbes, adsorption to the soil media, and biological uptake remove pollutants from the runoff. Excess sediment is filtered out by the soil media. The goal of bioretention is to treat runoff near its source, in contrast to end-of-pipe BMPs. Numerous rain gardens can be integrated into the landscape of a site.

Bioretention appears to be a promising remediation strategy for thermal pollution in developing cold water stream watersheds. Studies have already shown that a properly designed and installed bioretention facility is an effective method of reducing runoff quantity and improving the water quality. Data also shows that it may have the potential to cool runoff before discharging into the stormwater system. However, there is much more to learn 
about how bioretention affects runoff temperatures. This study hopes to provide insight into how bioretention functions as a thermal pollution remediation strategy.

\subsection{Problem Statement}

The purpose of this study is to evaluate the effectiveness of bioretention as a thermal pollution mitigation strategy. More specifically, the influent and effluent temperatures were measured to determine the effect bioretention has on runoff temperature. Bioretention and other LID practices have been extensively used to treat the water quality and quantity issues that are associated with urbanization. The hypothesis of this research is that this practice can be adapted to treat high temperature urban runoff that can damage thermally sensitive waterways.

\subsection{Objectives}

The primary objectives of this research include:

1) Evaluate the effectiveness of bioretention to mitigate thermal pollution associated with urban stormwater runoff.

It is important to study whether bioretention is an effective means of mitigating thermal pollution. Many studies have shown that urbanization results in high stormwater runoff temperatures and the degradation of cold water stream habitats. Few, however, have assessed the viability of bioretention, and other LID practices, to treat the thermal pollution associated with land development.

2) Assess how bioretention attenuates the inflow bydrograph during an event and what effect that has on thermal treatment.

Implementing a bioretention facility is known to attenuate the hydrograph of the stormwater leaving the site. This reduces the peak of the hydrograph and extends the tail. This study attempts to analyze the effect that this attenuation will have on the thermal flux entering the stream. It is expected that it reduces the thermal impact when compared with directly discharging untreated stormwater. 
3) Provide recommendations on how to use bioretention as a thermal pollution remediation strategy, if effective, to protect cold water stream ecosystems.

Even though thermal pollution is a documented problem in developing cold water stream watersheds, few instructions presently exist on how to use LID practices to mitigate this. If bioretention is found to be an effective strategy, this study hopes to provide some recommendations on how to best use bioretention for treating thermally charged stormwater. These details would be provided in bioretention design specifications so that temperature considerations are included in the design of future facilities. 


\section{Chapter 2}

\section{Literature Review}

\subsection{Thermal Pollution Due to Urbanization}

Urbanization is the product of a growing and developing population. An alteration of land cover is inevitable with this new development. The natural cover of watersheds is replaced with expanses of impervious surface. Klein (1979) discovered a trend where observed water temperatures rise in watersheds with increasing impervious cover. These impervious surfaces, especially without canopy cover, absorb heat much faster than any natural cover. While experimenting with thermal characteristics of stormwater runoff, Thompson et al. (2008) found asphalt to be particularly good at absorbing and storing thermal energy. An average temperature of $43.6^{\circ} \mathrm{C}$ for asphalt was reported versus an average temperature of only $23.3^{\circ} \mathrm{C}$ for turfgrass sod under the same conditions. Thompson and Wilson et al. (2008) reported an average runoff temperature from an asphalt parking lot for 15 events to be $29.8^{\circ} \mathrm{C}$.

A hydro-thermal model to quantify the impact that urban development in cold water stream watersheds has on stream temperature was created by Janke et al. (2009). It was stated that the runoff from a 0.58 acre parking lot during a mid-August rainfall event of only $0.33 \mathrm{~cm}$ produced a heat export of more than $250 \mathrm{MJ}$ when related to a temperature of $20^{\circ} \mathrm{C}$. That heat energy would be the equivalent received by a stream with a normal temperature of $20^{\circ} \mathrm{C}$ if the runoff was totally unmitigated. It has been determined that high initial pavement temperatures pose the greatest risk of thermal impact on the receiving stream. This scenario is most likely to occur during late summer and early fall when afternoon or early evening rainfalls occur after hot, dry days. Altering the slope or dimensions of parking lots is not enough to remedy the thermally charged runoff because it has been found by Herb et al. (2009) that altering these parameters by $\pm 20 \%$ produced less than $1^{\circ} \mathrm{C}$ change in runoff temperature. 


\subsection{Impacts on Cold Water Streams}

Coldwater streams are a unique habitat that are being encroached upon and degraded by increasing urbanization. A coldwater stream is defined as a stream that supports trout and other coldwater fish species according to Eaton et al. (1995). These ecosystems support a range of thermally sensitive organisms. Wang and Kanehl (2003) found that the most important environmental factor that affects assemblages of cold water macroinvertebrates in urbanizing watersheds is the percentage of urban land use in the watershed. Macroinvertebrate populations suffer greatly once impervious levels in a watershed exceed 10 percent. The impervious threshold decreases 1-2 percent for cold water streams compared to warm water streams, meaning that cold water streams are more prone to damage by low level urban development. It was also stated that water temperature is at least as important as urban land use when looking at the effects of urbanization on assemblages of macroinvertebrates in cold water streams.

Trout are native to cold water streams throughout the United States. They are very sensitive to abrupt temperature changes. Coutant (1977) found that trout prefer to avoid water temperatures exceeding $21^{\circ} \mathrm{C}$. Once temperatures rise above that level, mortality rates begin to increase according to Lee (1980). A study by Matthews et al. (1994) showed that trout tend to occupy a temperature range between $12.8^{\circ} \mathrm{C}$ and $19.1^{\circ} \mathrm{C}$. Edwards et al. (1979) stated that temperature not only influences mortality in trout species, but it also affects feeding, spawning, overall health, and growth. It has been observed by Matthews et al. (1997) that trout will actually select cool water, even if it is low in oxygen. This suggests that thermal pollution remediation in developing cold water stream watersheds is significant to protecting sustainable trout fisheries.

The Commonwealth of Virginia regulates water temperature based on seven water types. The maximum allowable temperature listed for trout sensitive waters is $21^{\circ} \mathrm{C}$, and limited to only $20^{\circ} \mathrm{C}$ in natural trout waters. In addition, the Virginia Code regulates a maximum rise above the natural temperature and a maximum hourly temperature change for point sources. The maximum rise above the natural temperature in not permitted to exceed $3^{\circ} \mathrm{C}$, and for Class VI waters (natural trout waters) it cannot exceed $1^{\circ} \mathrm{C}$. The maximum hourly temperature change is not permitted to exceed $2^{\circ} \mathrm{C}$, and for Class VI waters (natural trout waters) cannot exceed $0.5^{\circ} \mathrm{C}$. Table 2.1 is taken from 9VAC25-260 Virginia Water Quality Standards, Statutory Authority: $₫ 62.1-44.153$ a of the Code of Virginia. 
Table 2.1: 9VAC25-260-50. Numerical criteria for dissolved oxygen, $\mathrm{pH}$, and maximum temperature.***

\begin{tabular}{|c|c|c|c|c|c|}
\hline \multirow[t]{2}{*}{ Class } & \multirow[t]{2}{*}{ Description of Waters } & \multicolumn{2}{|c|}{$\begin{array}{l}\text { Dissolved Oxygen } \\
(\mathrm{mg} / \mathrm{L})^{* * * *}\end{array}$} & \multirow[t]{2}{*}{$\mathrm{pH}$} & \multirow{2}{*}{$\begin{array}{c}\text { Max. Temp } \\
\left({ }^{\circ} \mathrm{C}\right)\end{array}$} \\
\hline & & Min. & Daily Avg. & & \\
\hline $\mathrm{I}$ & Open Ocean & 5.0 & - & $6.0-9.0$ & - \\
\hline II & $\begin{array}{l}\text { Estuarine Waters (Tidal Water- } \\
\text { Coastal Zone to Fall Line) }\end{array}$ & 4.0 & 5.0 & $6.0-9.0$ & - \\
\hline III & $\begin{array}{l}\text { Nontidal Waters (Coastal and } \\
\text { Piedmont Zones) }\end{array}$ & 4.0 & 5.0 & $6.0-9.0$ & 32 \\
\hline IV & Mountainous Zones Waters & 4.0 & 5.0 & $6.0-9.0$ & 31 \\
\hline $\mathrm{V}$ & Stockable Trout Waters & 5.0 & 6.0 & $6.0-9.0$ & 21 \\
\hline VI & Natural Trout Waters & 6.0 & 7.0 & $6.0-9.0$ & 20 \\
\hline VII & Swamp Waters & $*$ & $*$ & $3.7-8.0^{*}$ & $* *$ \\
\hline
\end{tabular}

*This classification recognizes that the natural quality of these waters may fluctuate outside of the values for D.O. and $\mathrm{pH}$ set forth above as water quality criteria in Class I through VI waters. The natural quality of these waters is the water quality found or expected in the absence of human-induced pollution. Water quality standards will not be considered violated when conditions are determined by the board to be natural and not due to human-induced sources. The board may develop site specific criteria for Class VII waters that reflect the natural quality of the waterbody when the evidence is sufficient to demonstrate that the site specific criteria rather than narrative criterion will fully protect aquatic life uses. Virginia Pollutant Discharge Elimination System limitations in Class VII waters shall not cause significant changes to the naturally occurring dissolved oxygen and $\mathrm{pH}$ fluctuations in these waters.

**Maximum temperature will be the same as that for Classes I through VI waters as appropriate.

***The water quality criteria in this section do not apply below the lowest flow averaged (arithmetic mean) over a period of seven consecutive days that can be statistically expected to occur once every 10 climatic years (a climatic year begins April 1 and ends March 31). See 9VAC25-260-310 and 9VAC25-260-380 through 9VAC25-260-540 for site specific adjustments to these criteria.

****For a thermally stratified man-made lake or reservoir in Class III, IV, V or VI waters that are listed in 9VAC25-260-187, these dissolved oxygen criteria apply only to the epilimnion of the water body. When these waters are not stratified, the dissolved oxygen criteria apply throughout the water column. 


\subsection{BMPs}

Herb, Mohseni, and Stefan (2009) developed a numeric model to simulate the hydraulic and heat transfer characteristics of a stormwater detention pond in Minnesota. An unshaded pond was evaluated for thermal mitigation of runoff from paved surfaces. The evaluation combined simulated runoff from an asphalt parking lot for six years of observed events with the pond model. It was discovered that the pond outflow temperature was an average of $1.2^{\circ} \mathrm{C}$ higher than the inflow temperature. It was stated that the pond actually added heat energy to the runoff from an asphalt parking lot, on average. The rate of heat flow out of the pond was reduced by an order of magnitude due to reductions in the volumetric outflow. This decrease in heat flow reduced the temperature impacts in the receiving stream. However, the duration of the impacts were increased.

Kieser et al. (2004) showed that a stormwater wetland could mitigate thermal pollution, provided that it was well shaded. Cooling in stormwater wetlands was limited to the air temperature. Stormwater wetlands generally do not reduce runoff volumes significantly, so heat flow reduction through volume reduction is not very effective. In order for stormwater wetlands to function as a thermal pollution mitigation technique, sufficient cooling had to take place within the BMP.

Barbis et al. (2010) looked at the temperature mitigation benefits of porous pavements. It was found that porous pavement treats heated runoff in two ways. First, the limestone gravel that makes up the infiltration bed under the porous pavement maintains a cooler temperature, so as heated runoff comes in contact with the gravel it is cooled. Second, infiltration reduces the volume of heated runoff since it percolates into the ground and becomes part of the cooler baseflow. Porous pavement presents several challenges though. Its failure rate is high as it is easily clogged with sediment, which is nearly impossible to remove; also, it functions poorly in areas of low soil permeability.

Bioretention is a water quality and water quantity control practice that is used in an effort to maintain the pre-development hydrology of a site after development. According to Davis et al. (2009), it is one of the most frequently used stormwater control practices in urbanized watersheds. It has been shown to reduce sediment and pollutant loads, as well as mitigate an increased peak flow associated with urbanization (Davis, $2007 \& 2008$ ). Bioretention uses the chemical, biological, and physical properties of plants, soils, and microbes to remove pollutants from stormwater runoff. It also reduces runoff volume through retention and evapotranspiration (Prince George's County "Bioretention Manual", 2007). In contrast, Jones et al. (2007) found that stormwater wetlands and wet ponds actually increase the 
thermal pollution of stormwater runoff. Bioretention appears to be one of the most viable options for reducing thermal pollution in cold water stream watersheds.

Davis et al. (2009) observed that research involving other water quality parameters such as temperature attenuation is necessary. Jones and Hunt (2009) completed a study in North Carolina which examined the effect of bioretention areas on runoff temperatures for a series of natural rainfall events. It was concluded that bioretention is potentially a viable option for reducing the thermal pollution associated with urban stormwater runoff. With continued research it can be determined whether bioretention is a practice that can be implemented in different regions to protect cold water stream ecosystems from thermal pollution in urbanizing watersheds.

\subsection{Summary}

Urbanization of a watershed is proven to result in some degree of thermal pollution. The increased impervious surface area associated with development alters the natural hydrology of the watershed and causes an increased heat energy load in stormwater runoff. This increased thermal pollution in developing watersheds is detrimental to cold water stream ecosystems. It has been shown that even small temperature increases in cold water streams can drastically affect aquatic organisms such as macroinvertebrates and trout. A temperature of $21^{\circ} \mathrm{C}$ appears to be the threshold above which trout begin to become affected.

Several low impact development practices have been studied in terms of their thermal effects on stormwater runoff. Detention ponds and stormwater wetlands can actually increase runoff temperatures. Pervious pavements have been shown to have temperature reducing properties. However, a large portion of their success is through infiltration which is not feasible in all regions of the country. Bioretention is a BMP that has the potential to reduce thermal loads. Since bioretention is already known to be an effective water quantity and quality management practice, more research needs to be completed on the feasibility of bioretention as a thermal pollution reduction strategy in developing cold water stream watersheds. 


\section{Chapter 3}

\section{Methods}

\subsection{Site Selection}

While selecting a site for this study, several bioretention facilities around the town of Blacksburg, Virginia were considered. The major factors that were taken into consideration include:

1. Site provided an accurate representation of a bioretention facility.

2. Facility produced outflow when visited during a significant rainfall event.

3. Treated area had sufficient impervious surface exposed to solar radiation.

4. Inlets and outlets were accessible for temperature and flow measurements.

5. A water source was available at the site.

A facility that was built to current recommended bioretention specifications was desired. The necessary elements for this region include: liner, underdrain, engineered soil media, mulch layer, and sufficient vegetation. It was desired that the design plans or as-built plans be available for the bioretention facility.

A number of bioretention facilities did not produce outflow when visited shortly after a significant rainfall event. These were not desirable because either the liner was damaged and runoff was escaping into the ground or it would require too much runoff to see a reasonable outflow.

It was necessary that the study site had a parking lot that was exposed to solar radiation to get sufficient heating of the simulated runoff. A larger parking lot would allow for more 
surface area and more contact time, therefore increasing the heat energy transferred to the runoff. An asphalt parking lot was preferred since studies have shown asphalt to be a significant contributor to thermal pollution.

The inlets and outlets of the facility must be accessible in order to place the temperature data loggers and to record flows. Most outlets released directly to the underground storm sewer system, making outflow measurements difficult. Another promising site released the outflow into underground detention so outflow and temperature measurements were infeasible.

A water source was required on site. A fire hydrant was selected as a water source because it was capable of providing flow rates comparable to a small rainfall event. The proximity of the fire hydrant to the parking lot was also a consideration.

The only site that was considered that met all of these specifications was located at the Community and Aquatic Centers in Blacksburg, Virginia. There are two bioretention facilities at the site. One is designed to treat the Community Center parking lot and one is designed to treat the Aquatic Center parking lot. The Aquatic Center bioretention, though smaller, showed virtually no outflow during rainfall events. It was believed that the liner was compromised and that runoff was escaping the facility. The Community Center bioretention facility functioned well during rainfall events, met all of the above specifications, and was ultimately selected for this study.

\subsection{Bioretention Site Specifications}

The bioretention facility used for this experiment is located at the base of the Community Center parking lot in Blacksburg, Virginia ( $37^{\circ} 14^{\prime} 37^{\prime \prime} \mathrm{N}$, $80^{\circ} 24^{\prime} 43^{\prime \prime} \mathrm{W}$ ). Blacksburg is located in southwest Virginia, between the Allegheny and Blue Ridge Mountains, in the Ridge and Valley Physiographic Province. The bioretention facility was designed to treat the entire 0.73 ha asphalt Community Center parking lot, and had a surface area of $100 \mathrm{~m}^{2}$. The BMP construction was completed in July 2007.

The bioretention dimensions were $27 \mathrm{~m}$ long, $3.7 \mathrm{~m}$ wide, and $1.3 \mathrm{~m}$ deep. It was filled with CU-Structural Soil ${ }^{\mathrm{TM}}$, which was developed at the Urban Horticulture Institute at Cornell University. It is approximately $80 \%$ stone and $20 \%$ clay/loam soil and held together with Gelscape ${ }^{\circledR}$ hydrogel. Gelscape ${ }^{\circledR}$ hydrogel is a potassium propenoate-propenamide copolymer manufactured by Amereq, Inc., New York City, New York. Its function is to promote the retention of both water and nutrients by adhering soil to gravel, while 
sustaining high porosity. The $15 \mathrm{~cm}$ liner was constructed by compacting clay soil. The entire basin was lined with LINQ GTF 130EX nonwoven filter fabric that is manufactured by LINQ Industrial Fabrics, Inc. in Summerville, South Carolina. The purpose of this nonwoven filter fabric is to prevent intrusion of the surrounding soil into the engineered soil or gravel bed. Two parallel $10 \mathrm{~cm}$ high density polyethylene (HDPE) pipes that are perforated, covered in filter fabric, and surrounded in \#57 stone make up the underdrain system. One meter of the CU-Structural Soil ${ }^{\mathrm{TM}}$ was placed above the drainage layer, followed by a layer of filter fabric, and topped off with a $10 \mathrm{~cm}$ mulch layer. An overflow structure was designed to activate once ponding in the depression exceeds $10 \mathrm{~cm}$. This structure also received the runoff from the underdrain system. It was connected to the existing stormwater system, with the outfall to a dry detention basin. To promote evapotranspiration, biological uptake, and beneficial microorganisms, trees, shrubs, and perennials were planted. (DeBusk, et al., 2009)

Figure 3.1: Aerial Image of Bioretention Facility and Treated Area

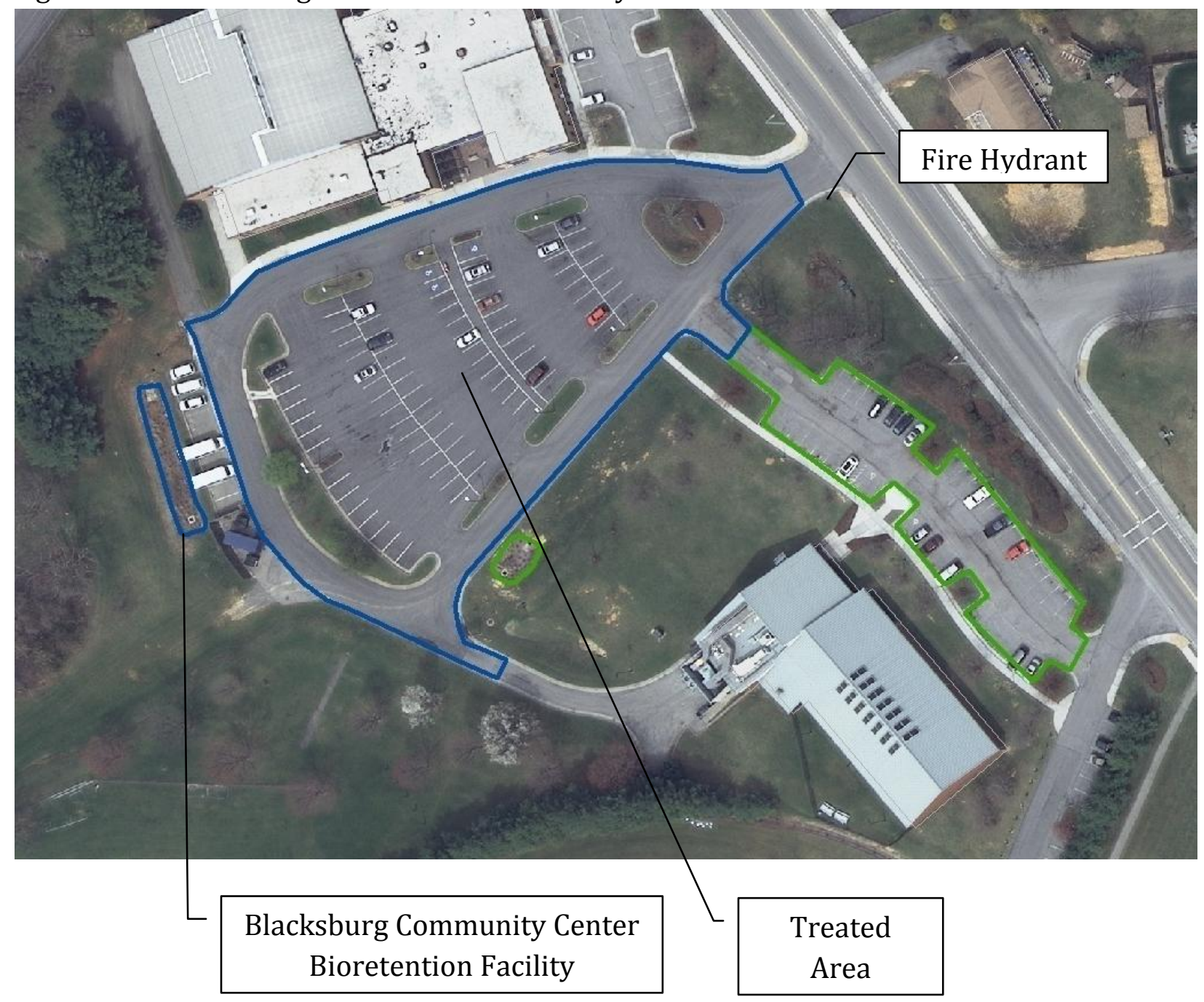


Runoff was routed to the bioretention facility by the slope of the parking lot. In a lower portion of the parking lot, a curb and gutter concentrated flow and routed it to a concrete channel where it was directed into the small lower parking lot. There was a short grassed channel that accepted all of the runoff from the parking lot and directed it into the inlet pipe of the bioretention facility.

\subsection{Materials and Methods}

To examine the effect that bioretention has on runoff temperatures in Southwest Virginia, a series of experiments was completed at the Community Center bioretention facility in the town of Blacksburg, Virginia. The study was accomplished in a series of ten trials from July to September 2010. The trials were completed in the middle of the afternoon to maximize the asphalt temperatures in an attempt to observe peak runoff temperatures. Vegetative cover was estimated at $60 \%$ by using overhead images to determine the amount of canopy cover versus exposed mulch in the bioretention facility. Canopy cover shades the vegetated bioretention facility from solar radiation and provides increased surface area for evapotranspiration to occur. Air temperatures at the time of the experiments were recorded at the Weather Center of the Virginia Tech Montgomery Executive Airport in Blacksburg, Virginia. A minimum of 48 hours was allowed between experiments to provide time for the bioretention facility to process the runoff and for the soil media to dry. If a rainfall event occurred, a minimum of 48 hours from the end of the event was allowed before the next trial was completed.

A controlled water source was chosen instead of relying on inherently variable and unpredictable natural rainfall events. A fire hydrant on site was used as the water source. A water gauge was attached to the hydrant to record the volume of water used, in gallons. Once the hydrant was opened, a valve on the water gauge was used to increase the flow in three increments to create a hydrograph. By recording the volume used during each increment, average flow rates were calculated. The initial water temperature was measured with a temperature probe at the fire hydrant. A fire hose was used to convey the water from the hydrant to the parking lot where it was sprayed onto the asphalt surface. The water then travelled as sheet flow across the parking lot and flowed towards the bioretention facility. The runoff absorbed heat energy from the asphalt, similar to what would be expected during a natural late-afternoon summer rainfall event. This heated runoff concentrated at the base of the parking lot. An 8 foot long grass channel, where minor cooling likely occurred, carried the flow to the smooth plastic inlet pipe of the bioretention facility. 
Temperature measurements were collected with two $\mathrm{HOBO}{ }^{\circledR}$ Pendant Temperature Data Loggers (UA-001-08), manufactured by Onset Computer Corporation, Bourne, Massachusetts. The temperature data loggers were placed inside the inlet pipe and the outlet structure. They were programmed to record temperatures every 5 seconds. These data loggers recorded the temperatures of the influent and effluent. These inlet and outlet temperatures were used to assess the effectiveness of the bioretention facility at cooling the heated simulated stormwater runoff.

Since the initial flow rates were known, it was also desirable to find the outflow rates from the bioretention facility. The outflow rates were measured where the outlet structure of the bioretention facility outfalls to a dry detention basin. A bucket-and-stopwatch technique was used to measure the flow rate out of the bioretention facility. This is considered an offline approach since it cannot be done without interrupting the regular flow. The initial (hydrant) flow and outflow measurements were used to build hydrographs of the simulated event. Though the flow from the hydrant was measured, the actual inflow to the bioretention facility was not. Due to losses that occur across the parking lot, the flow from the hydrant and the actual inflow cannot be assumed to be identical. 


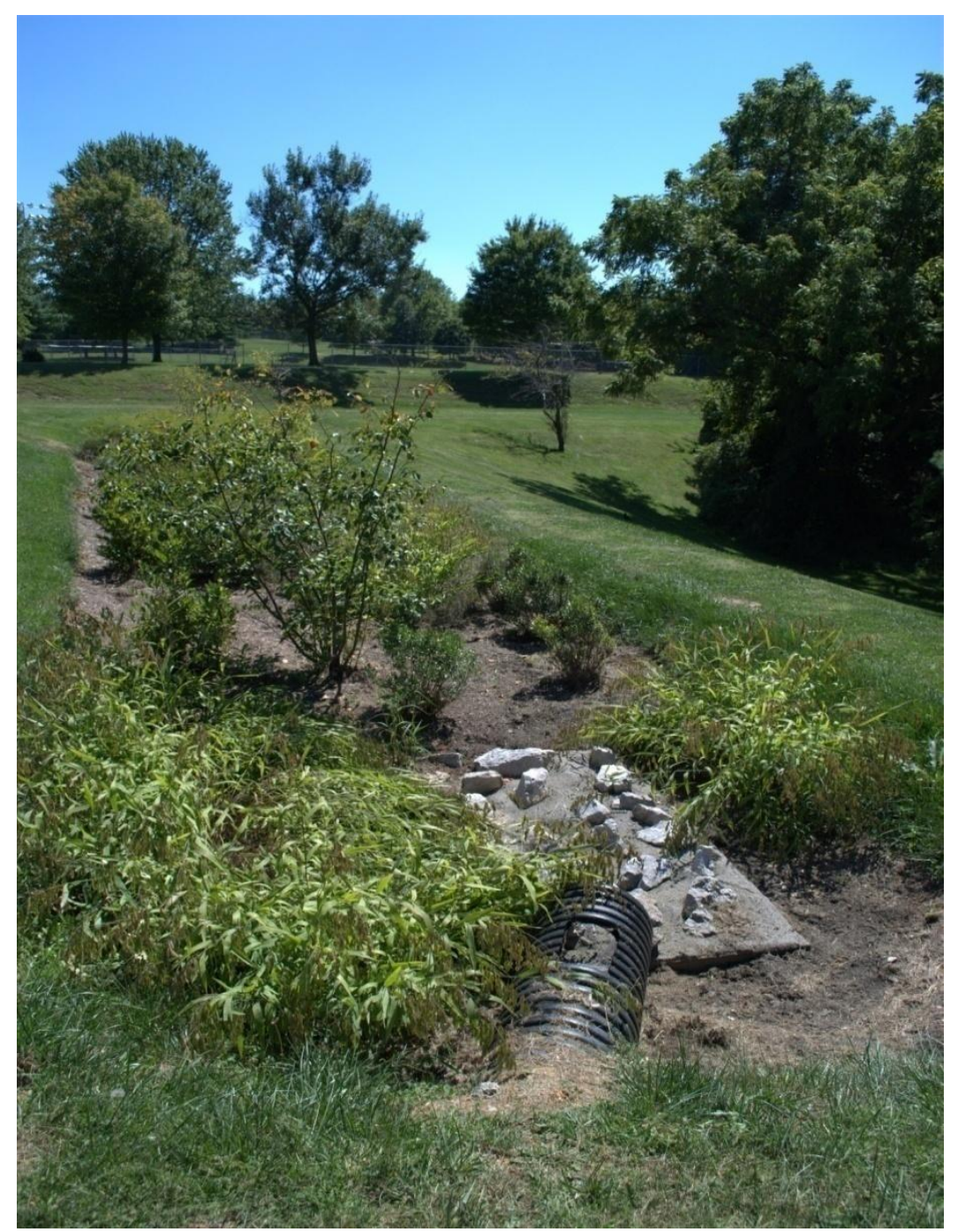

Figure 3.2: The Community Center Bioretention Facility that treats a 0.73-ha asphalt parking lot in Blacksburg, VA.

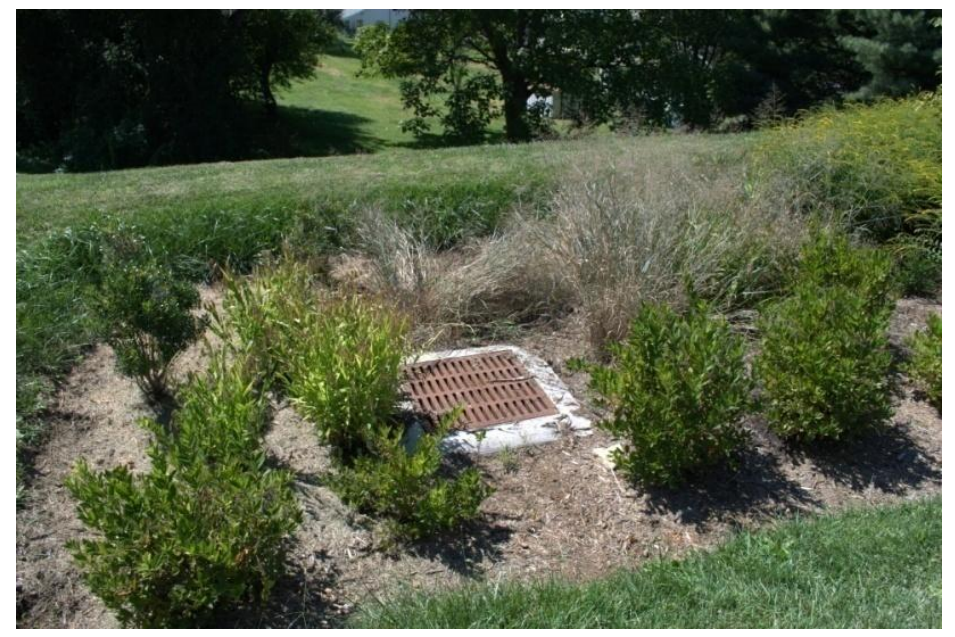

Figure 3.3: Overflow Structure at opposite end of bioretention facility. 


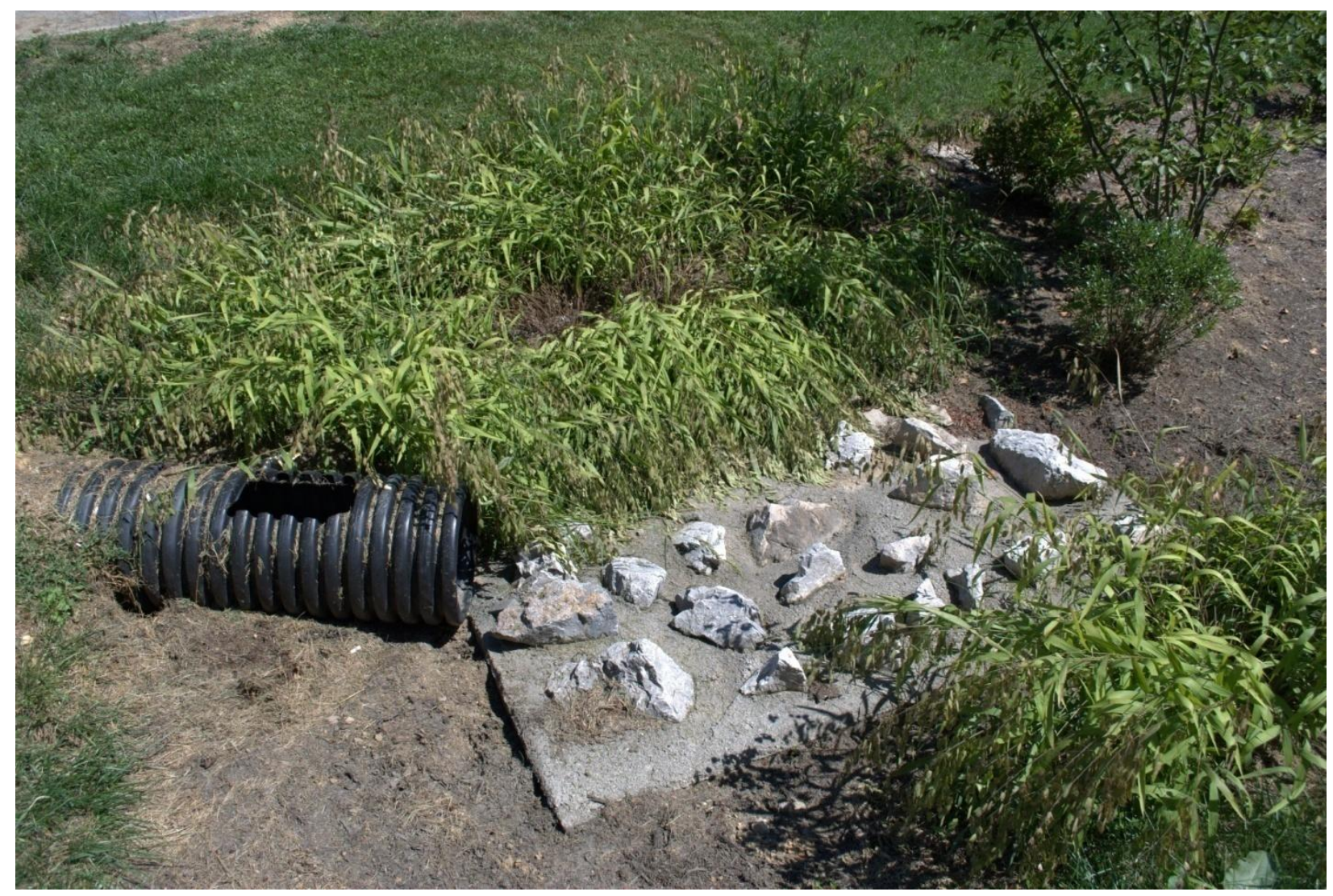

Figure 3.4: Inlet to Bioretention Facility.

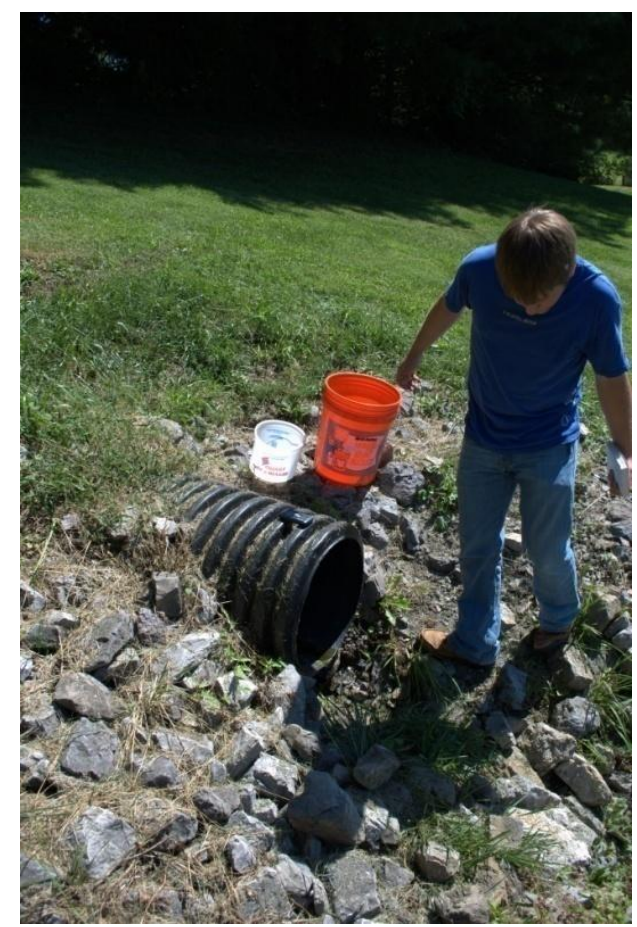

Figure 3.5: Outfall to Dry Detention Pond and location of outlet flow measurements. 


\section{Chapter 4}

\section{Results and Discussion}

Ten trials to study the thermal pollution mitigation effects of bioretention were completed.

Table 4.1 summarizes the data for all ten trials.

Table 4.1: Summary statistics for runoff temperatures (all units in ${ }^{\circ} \mathrm{F}$ unless otherwise specified)

\begin{tabular}{|c|c|c|c|c|c|c|c|c|c|c|c|c|}
\hline & Run 1 & Run 2 & Run 3 & Run 4 & Run 5 & Run 6 & Run 7 & Run 8 & Run 9 & Run 10 & Average & $\begin{array}{l}\text { Std. } \\
\text { Dev. }\end{array}$ \\
\hline Date & $8 / 11$ & $8 / 30$ & $9 / 1$ & $9 / 8$ & $9 / 10$ & $9 / 14$ & $9 / 16$ & $9 / 20$ & $9 / 22$ & $9 / 24$ & - & - \\
\hline Weather Conditions & Sunny & Sunny & Sunny & $\begin{array}{l}\text { Partly } \\
\text { Sunny }\end{array}$ & Sunny & Sunny & Cloudy & $\begin{array}{l}\text { Partly } \\
\text { Sunny }\end{array}$ & $\begin{array}{l}\text { Partly } \\
\text { Sunny }\end{array}$ & Sunny & - & - \\
\hline Air & 93 & 89 & 90 & 80 & 78 & 84 & 84 & 84 & 87 & 87 & 85.6 & 4.6 \\
\hline Initial Water & 70 & 70 & 68 & 69 & 71 & 70 & 70 & 70 & 71 & 71 & 70 & 0.9 \\
\hline Inflow Average & 96.1 & 98.4 & 98.0 & 88.6 & 92.4 & 95.8 & 82.9 & 92.8 & 93.4 & 93.1 & 93.2 & 4.6 \\
\hline Outflow Average & 82.9 & 76.7 & 79.2 & 76.1 & 76.8 & 75.1 & 76.1 & 75.8 & 77.4 & 77.6 & 77.4 & 2.2 \\
\hline Inflow-Outflow Avg. & 13.2 & 21.7 & 18.8 & 12.4 & 15.6 & 20.7 & 6.8 & 17.0 & 16.1 & 15.5 & 15.8 & 4.3 \\
\hline Inflow Maximum & 98.1 & 101.5 & 102.7 & 91.6 & 94.6 & 100.5 & 84.8 & 94.8 & 97.5 & 95.0 & 96.1 & 5.3 \\
\hline Outflow Maximum & 86.6 & 79.5 & 83.0 & 79.3 & 80.4 & 77.6 & 79.0 & 78.8 & 80.9 & 81.4 & 80.7 & 2.6 \\
\hline Inflow-Outflow Max. & 11.5 & 22.0 & 19.7 & 12.3 & 14.3 & 22.9 & 5.9 & 16.0 & 16.6 & 13.6 & 15.5 & 5.2 \\
\hline Volume Released (cu. ft.) & 746.5 & 545.3 & 585.6 & 441.1 & 467.7 & 352.7 & 427.7 & 481.2 & 521.4 & 454.5 & - & - \\
\hline Volume Treated (cu. ft.) & 710.1 & 453.8 & 498.4 & 426.8 & 404.1 & 345.5 & 411.7 & 455.3 & 445.1 & 308.1 & - & - \\
\hline
\end{tabular}

A review of Table 4.1 leads to some interesting observations:

○ The average influent temperature for the ten trials was $93.2^{\circ} \mathrm{F}$, while the average effluent temperature was $77.4^{\circ} \mathrm{F}$.

- This bioretention facility cooled the heated runoff an average of $15.8^{\circ} \mathrm{F}$. The minimum average temperature reduction for an individual trial was $6.8^{\circ} \mathrm{F}$ and the maximum was $21.7^{\circ} \mathrm{F}$. 
O The maximum recorded temperature at the inlet was $102.7^{\circ} \mathrm{F}$, which occurred during Run 3. The $34.7^{\circ} \mathrm{F}$ increase that occurred during that run was the largest temperature increase of sheet flow as it crossed the asphalt parking lot. The bioretention reduced this peak temperature to $83^{\circ} \mathrm{F}$, for a reduction of $19.7^{\circ} \mathrm{F}$.

○ The maximum recorded outlet temperature of $86.6^{\circ} \mathrm{F}$ was recorded during Run 1.

- The greatest average temperature reduction of $21.7^{\circ} \mathrm{F}$ occurred during Run 2 when $545 \mathrm{cu}$. ft. of water was released onto the parking lot and $454 \mathrm{cu}$. ft. was treated. The greatest average inflow temperature of $98.4{ }^{\circ} \mathrm{F}$ also occurred during this run.

- The greatest inflow maximum to outflow maximum thermal reduction was 22.9 ${ }^{\circ} \mathrm{F}$ and occurred during Run 6. This run corresponds with the lowest water volume that was released onto the parking lot which was $353 \mathrm{cu}$. ft., of which 346 cu. ft. was treated.

- Run 6 also results in the lowest average and peak temperatures of the outflow of $75.1^{\circ} \mathrm{F}$ and $77.6^{\circ} \mathrm{F}$ respectively. This may indicate that bioretention has a greater cooling effect on lower volumes of urban stormwater runoff.

○ On the hottest day of the study the air temperature was $93^{\circ} \mathrm{F}$, but neither the highest inflow average temperature nor peak temperature was attained. This can be explained by cloud cover. Though it was a hot humid day, cloud cover reduced the amount of solar radiation available to the parking lot asphalt. The highest runoff temperatures were observed after sunny days when the asphalt was exposed to solar radiation and then transferred the heat energy to the simulated runoff.

- Run 6, Run 7, and Run 8 have identical air and hydrant temperatures, but since it was sunny during Runs 6 and 8 the average and maximum inflow temperatures are $\geq 10{ }^{\circ} \mathrm{F}$ warmer than those recorded during Run 7 when it was cloudy. Surprisingly, the average and maximum outflow temperatures are slightly cooler for the sunny days compared to the overcast day. 
- The standard deviation of the average inflow temperatures was 4.6, while it was only 2.2 for the average outflow temperatures. This trend continued for the maximum temperatures. The standard deviation of the maximum inflow temperatures was 5.3, while it was only 2.6 for the maximum outflow temperatures. This shows that inflow temperatures were more variable than the outflow temperatures.

When compared to the adopted threshold of $69.8^{\circ} \mathrm{F}\left(21^{\circ} \mathrm{C}\right)$ from Coutant (1977), both the average influent and effluent temperatures exceed the threshold temperature. However, with a temperature decrease observed during each trial, this bioretention facility proved to successfully reduce runoff temperatures. Figure 4.1 shows the peak and average temperatures for each trial.

Figure 4.1: Peak and average temperatures for each trial

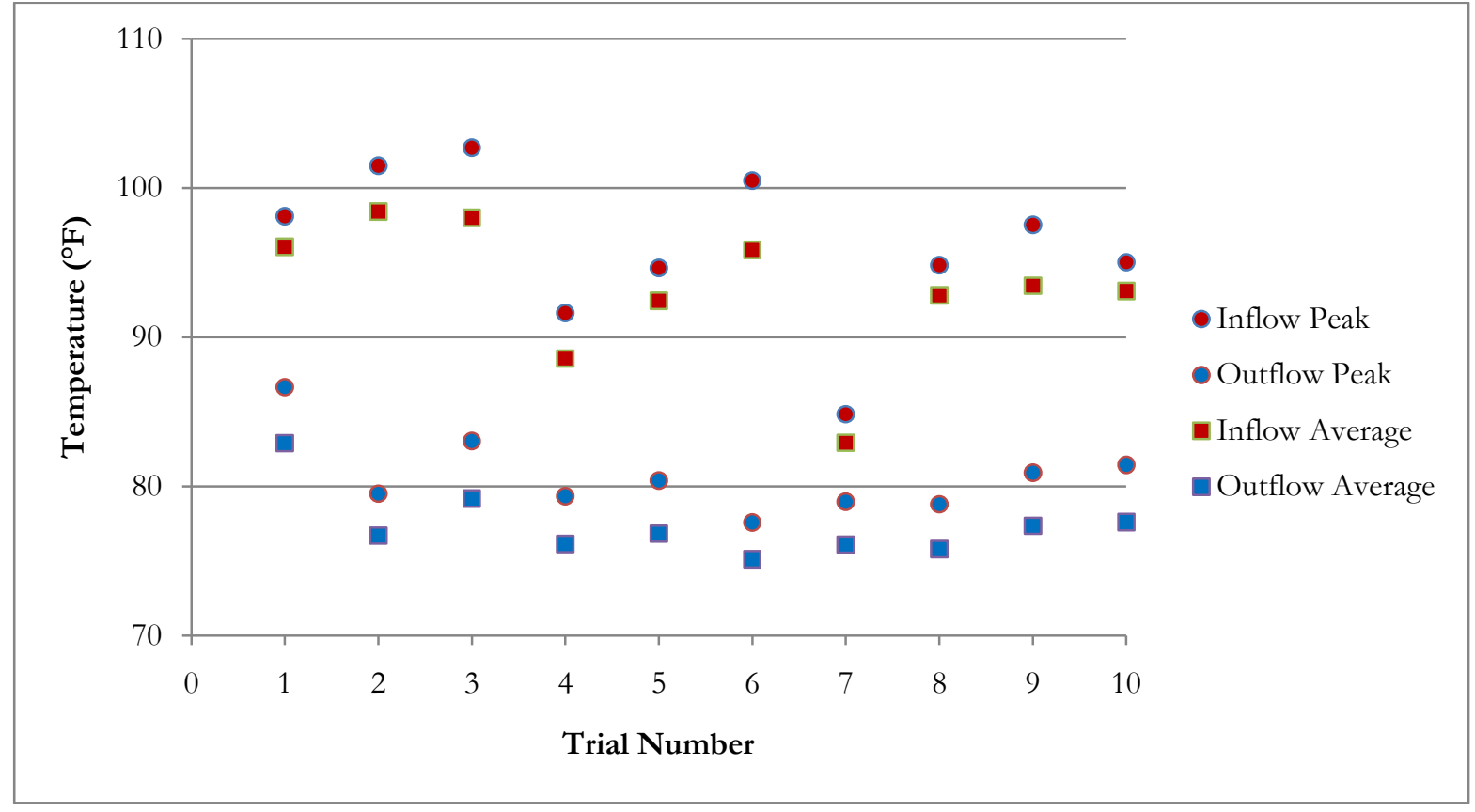

A regression analysis was completed to compare the temperature increase of sheet flow across the parking lot to the air temperature. A relationship of $y=0.605 x-28.67$ was determined, with a coefficient of determination of 0.321. This result shows that approximately one-third of the temperature increase that occurs as runoff crosses the parking lot is explained by the air temperature.

Another regression analysis was completed to evaluate the effect that air temperature has on the temperature decrease of the heated runoff as it is treated by the bioretention facility. A 
relationship of $\mathrm{y}=0.208 \mathrm{x}-2.037$ was determined, with 0.047 as the coefficient of determination. This result shows that air temperature likely does not significantly influence the cooling associated with bioretention. It makes sense that the soil media in a bioretention facility maintains a fairly consistent temperature despite changes in the air temperature since it is in a buffered state below ground and covered with a mulch layer.

Figure 4.2: Temperature increase across the parking lot versus the air temperature

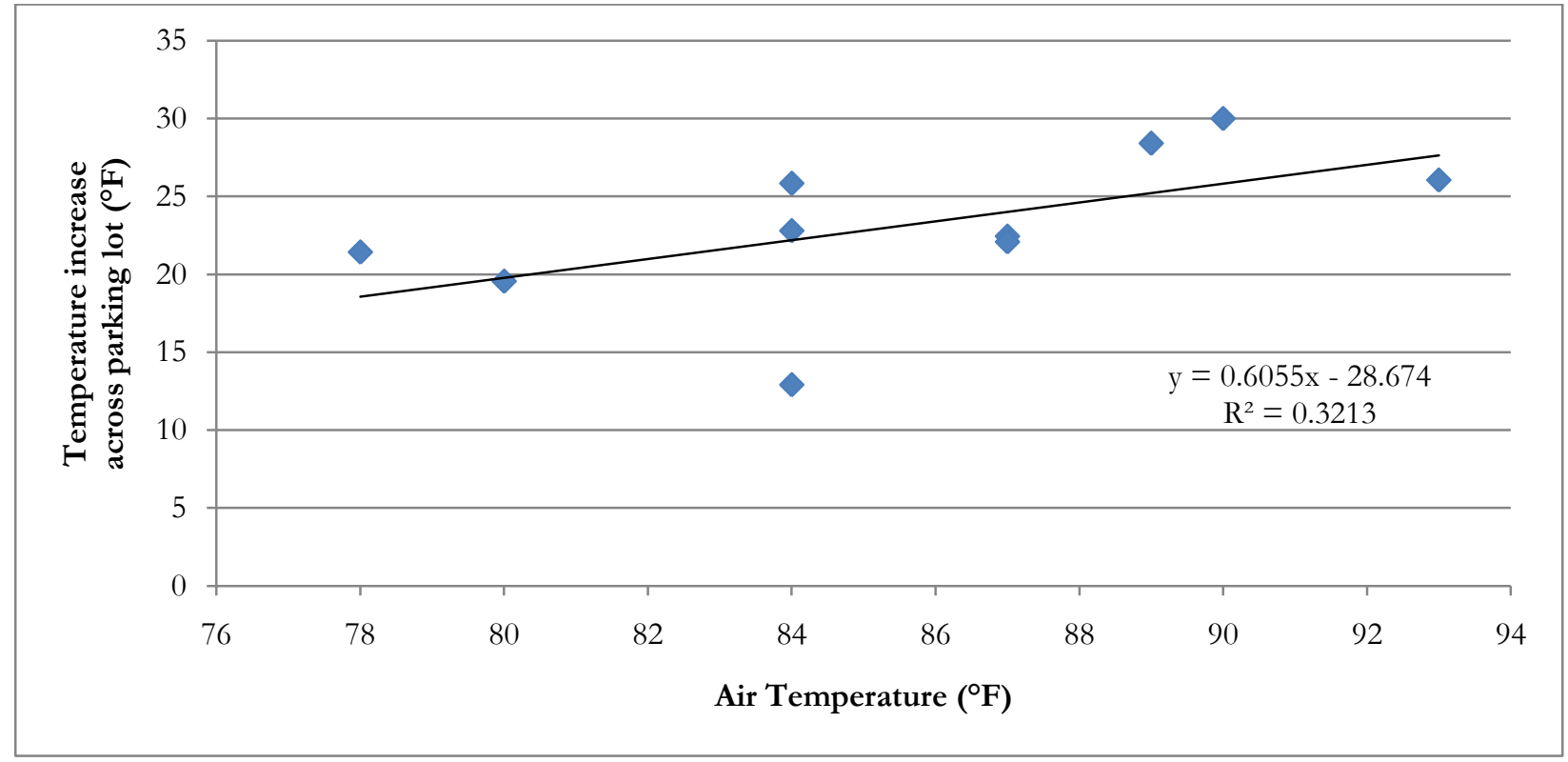

Figure 4.3: Thermal reduction through bioretention versus the air temperature

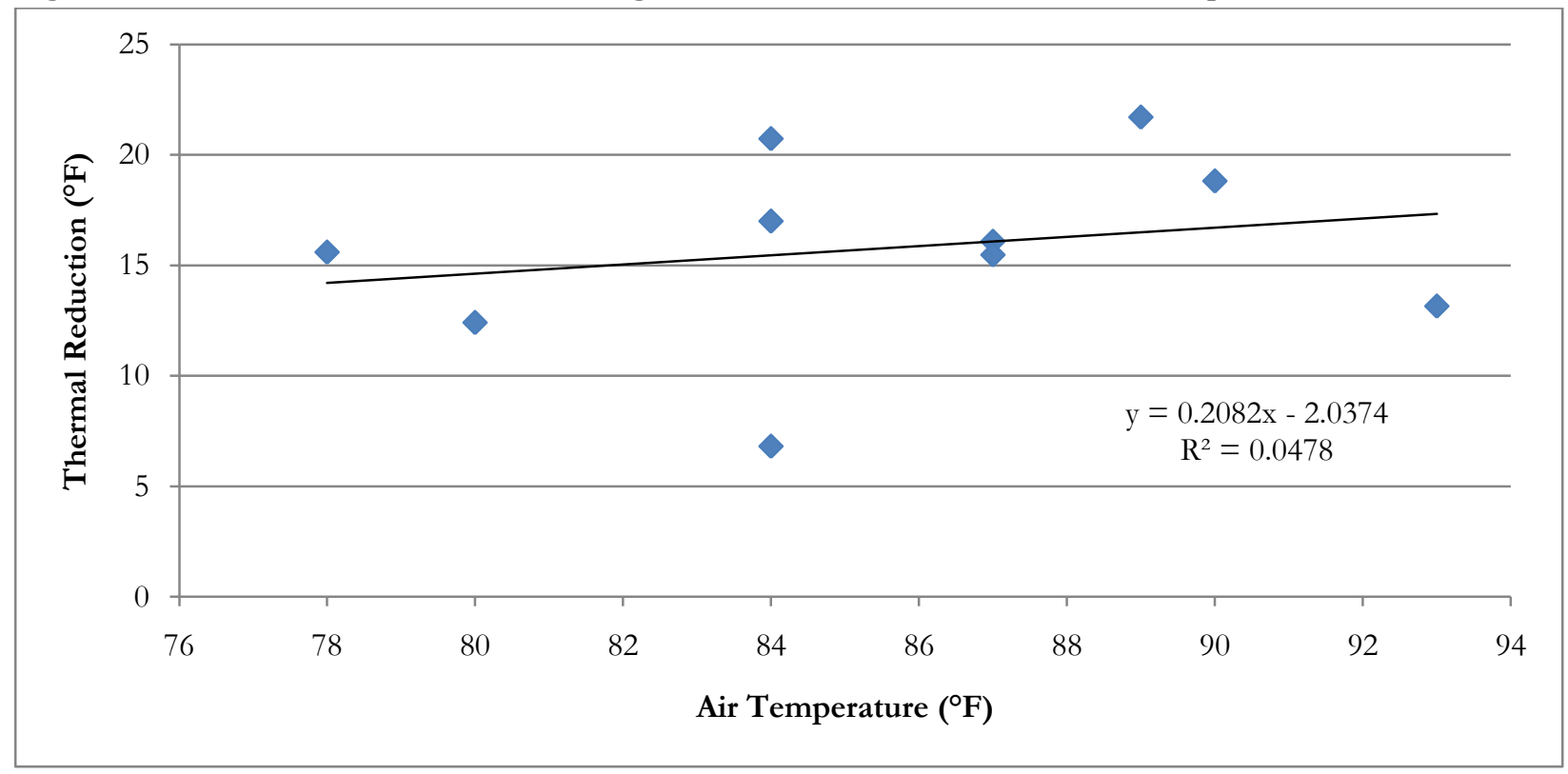


Solar radiation is a major factor in the amount of thermal energy stored in an asphalt surface, and consequently the amount of thermal energy in the runoff from the asphalt surface. It is expected that when impervious cover is heated up, a greater temperature reduction from bioretention will be observed. This is due to the fact that bioretention soil media is buffered against significant temperature changes from radiation and convection, which essentially puts a lower limit on the temperature that can be achieved by a particular bioretention facility. Since the low-end temperature is limited, increased temperature reduction would be achieved as inflow temperatures increase. Since standard deviation is a measure of variability, comparing the standard deviations shows that the outflow temperatures are less variable than the inflow temperatures. Additionally, the smallest temperature decrease through the bioretention was observed during the cloudy day, even though air and initial water temperatures showed no significant variation from the sunny days. Assuming that a bioretention facility is well buffered by mulch and vegetation, it should be expected that any increase in solar radiation prior to a rainfall event would result in a greater observed runoff temperature reduction.

An additional regression analysis was completed to analyze the effect that the volume of water treated has on the temperature reduction that occurs in the bioretention facility. A relationship of $y=-0.005+18.06$ was determined, with a coefficient of determination of 0.016 .

Figure 4.4: Thermal reduction through bioretention versus the volume of runoff treated

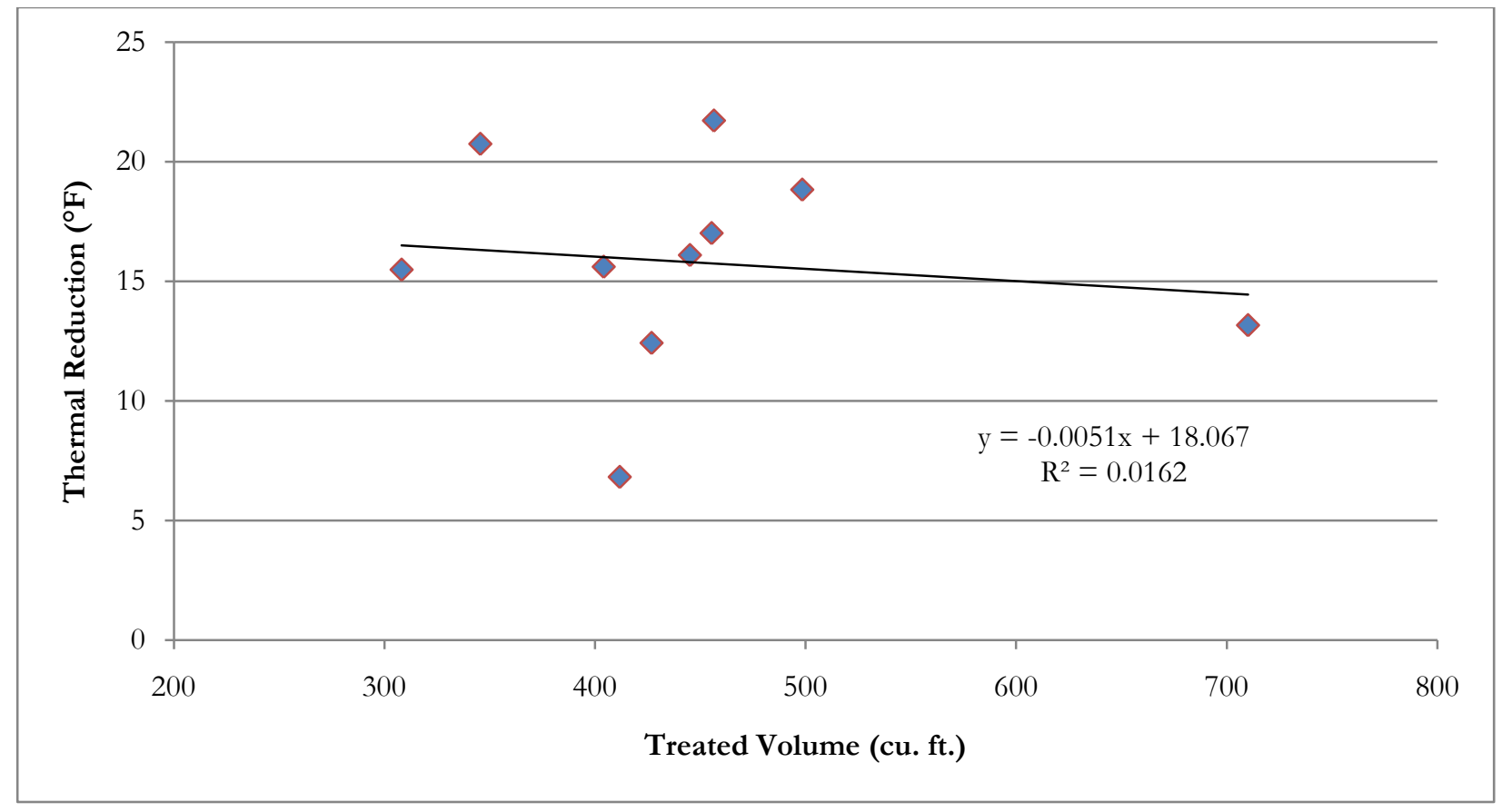


This result shows that there is a slight negative correlation, meaning as treated runoff volume increases the thermal reduction from the bioretention decreases. While the runoff volume likely affects the treatment ability of a bioretention facility, there are other factors that also play a major role. An outlier was determined to be Run 7, when cloudy conditions limited the inflow temperatures. Increasing the number of trials and varying the volumes to a larger degree would likely produce data that results in a better fit and produce more statistically significant findings.

Between the hydrograph from the hydrant and the outflow hydrograph from the bioretention facility, an average peak reduction of $50.5 \%$ was observed for these ten runs. The greatest reduction was $61.5 \%$ and the least was $12.5 \%$. The latter was a result of a greater quantity of water used; $747 \mathrm{cu}$. $\mathrm{ft}$ compared to an average of $475 \mathrm{cu}$. ft. for the other nine runs, ranging from 353 to $586 \mathrm{cu}$. ft. The runoff lag time was increased an average of 19.6 minutes through this bioretention facility. The duration of the hydrograph was increased over $500 \%$ for every run.

Unfortunately, the hydrograph attenuation associated with this bioretention facility was unable to be definitively determined in this study. The bioretention facility was shown to reduce the peak flow and increase the runoff lag time using the hydrograph from the hydrant flows as the initial hydrograph. These effects are considered the fundamental objectives of bioretention as a LID practice. However, this is not a true inflow hydrograph because it is improbable that the bioretention provides 100 percent runoff capture. Runoff was lost through various processes which include the initial abstraction associated with asphalt, evaporation, infiltration, and topography. In addition, flow rates will vary across the parking lot so the flows are likely different by the time the runoff reaches the bioretention inlet. Therefore the true inflow hydrograph cannot be determined with this procedure. One of the primary principles of bioretention is to attempt to recreate the pre-development hydrology for a site; reducing the post-development peak flow and increasing the lag time to predevelopment levels is expected to reduce the thermal influx to a stream. 


\section{Chapter 5}

\section{Conclusions}

\subsection{Conclusions}

This study investigated the effect of bioretention on thermal pollution associated with urban stormwater runoff in developing cold water stream watersheds. The ability of bioretention to treat thermally charged runoff was assessed by comparing the inflow and outflow temperatures recorded at a bioretention facility. The study has come to several primary conclusions:

1. Bioretention is a viable option for the treatment of thermal pollution. During ten independent trials it was observed that this bioretention facility significantly reduced the average and peak temperatures of simulated runoff.

2. It was observed that larger runoff volumes likely reduced the cooling effects of the bioretention. This loss of effectiveness is likely due to a couple factors. First, the runoff moves quicker through the soil media due to the greater force of the larger volume of water behind it allowing less time for cooling. Second, conduction of heat energy occurs from the runoff to the bioretention soil media. This results in the soil media reaching a point where it is the same temperature as the runoff and heat transfer no longer occurs. A solution would be to design a larger bioretention facility to increase the volume of soil media available to store heat energy or to incorporate multiple smaller facilities. The depth of a bioretention facility increases its buffering ability, as well as increases the soil media volume of a facility.

3. Inflow temperatures were found to be more variable than outflow temperatures. This study compared the standard deviations of the inflow and outflow temperatures and 
determined that the outflow temperatures were more consistent. This is likely due to the buffering abilities of bioretention compared to the unpredictability of surface weather conditions.

4. Higher runoff temperatures that resulted in greater thermal reduction by the bioretention facility occurred during sunny days. Separate trials with identical air and hydrant temperatures but varying cloud cover showed that bioretention has the ability to treat the increased thermal load in runoff from asphalt heated by solar radiation.

5. This study was unable to quantify the hydrograph attenuation effects of this bioretention facility. Although the hydrograph attenuation benefits of bioretention were unable to be observed, there is a high likelihood that the water quantity benefits associated with bioretention could also reduce the impact of thermal pollution on streams.

\subsection{Future Work}

While this study has shown that the bioretention facility at the study site is capable of reducing thermal pollution, further research needs to be conducted for various facilities and locations to find if these results are consistent. Some suggestions for future work include:

- Further research efforts that study the effects that thermal pollution has on cold water stream ecosystems. It is necessary to know what treatment level BMPs must attain in order to be effective at mitigating the effects of thermal pollution from direct discharges.

- Develop equations for the design of bioretention facilities to obtain the desired thermal pollution treatment benefits. Similar experiments on bioretention facilities with various volumes, depths, engineered soil media, treatment volumes, and treatment areas, would determine the potential and limits of bioretention as a thermal pollution treatment strategy. It will become important to find and understand the design parameters that encourage maximum heat transfer in order to engineer the most effective bioretention facilities for a site.

- Examine the hydrograph attenuation effects of bioretention by incorporating flow meters at the inlet and outlet of the facility. Once true inflow and outflow hydrographs are recorded, any temperature benefits of the hydrograph attenuation associated with bioretention can be examined. 
- Model the thermal effects of bioretention by studying how heat migrates in this system. Temperature data loggers placed across the parking lot would allow for the quantification of the heat exchange which occurs between the asphalt and the runoff. It would also be advantageous to have temperature data loggers located at various depths in the bioretention facility to examine the thermal effects that occur during treatment. The ability to model temperature through BMPs would be a great asset in the implementation and design of bioretention facilities and other LID practices.

- Implement other runoff temperature reduction methods. Studies have shown asphalt to transfer the largest amount of heat energy to runoff compared with other land cover. Replacing asphalt with alternatives such as concrete or porous pavement in areas designated as having a high-risk of cold water stream habitat degradation may prove to be an effective strategy. Limiting connectivity of impervious area is another technique that upon further research may serve to reduce thermal impact on streams. This strategy increases the time of concentration, which reduces the peak flow and the size of the thermal flux the bioretention facility must treat. By incorporating landscape islands into impervious cover, a path of infiltration is provided for runoff to percolate to baseflow. This also reduces the contact time between the impervious surface and the sheet flow which provides less time for thermal energy to be transferred to the runoff.

- Analyze engineered soil media options for a mixture that is most effective at removing heat energy from thermally charged stormwater runoff. There are many options for bioretention media. Pre-mixed engineered soils are available, such as the CU-Structural Soil ${ }^{\mathrm{TM}}$ that was used in the bioretention facility that was the focus of this study. Bioretention media can also be made by mixing various sized sand and gravel to create a soil structure with the desired porosity.

- Use LID practices in sequence to treat runoff in an effort to enhance the effects of bioretention. It was shown that bioretention can treat smaller flows and volumes more effectively. It is feasible that the thermal effect of the bioretention treatment can be enhanced by reducing runoff flows and volumes prior to treatment. This could be accomplished by treatment with LID practices such as vegetated roofs, roof cisterns, vegetated swales, porous pavement, and other developing strategies before the runoff reaches the bioretention. 
- Study the disadvantages of bioretention as a thermal pollution treatment option. Continuing research should be conducted on the effects of elevated outflow temperatures from bioretention facilities during colder months. Elevated runoff temperatures during particular times of the year may have detrimental effects on cold water stream ecosystems, fish health and spawning, or the life cycles of macroinvertebrates.

\subsection{Final Words}

The overall goal of low impact development is to maintain the natural hydrology, habitat, and ecosystems of the site. In many regions, maintaining the natural temperature of runoff needs to be a major goal of LID design. The full extent of damage to cold water stream ecosystems due to thermally charged runoff is still being determined. Increasing jurisdictions are monitoring runoff and implementing temperature limits.

The use of bioretention as a thermal pollution treatment strategy is expected to be most effective in areas where the underlying soils have good hydraulic conductivity. In these regions infiltration into the underlying soil can be heavily relied on by leaving the base of the facility unlined and having a trench below the underdrain to act as a storage layer. An underdrain reduces the likelihood of an overflow occurring during larger events. The bioretention that was the focus of this study was designed following said plan, however, negligible infiltration was observed as would be expected for this region. Some designs may opt to eliminate the underdrain completely and depend entirely on infiltration. Infiltration would be the most effective measure of minimizing thermal pollution because all thermally charged runoff would be percolated to baseflow. Between the cooling that occurs while percolating and the dilution by the natural baseflow, by the time the runoff reaches a stream the thermal effects would likely be minimal or non-existent. This strategy also best mimics a sites natural hydrology by recharging the groundwater that feeds cold water streams. Eliminating the underdrain increases the risk of an overflow event occurring. However, any thermal event associated with an overflow cannot be worse than if no bioretention facility was present on site.

Bioretention, in its current state, cannot be viewed as a fix-all for thermal pollution. While it has the ability to reduce temperatures in heated runoff, the buffering ability of bioretention may actually heat runoff during colder months. The depth of a bioretention facility is what buffers the engineered soil media from the ambient air temperature and provides for the cooling effects on runoff during warm months. During cold months, the soil media in the 
bioretention facility is likely buffered at a warmer temperature than the surface temperature. This could actually warm runoff, resulting in higher than natural runoff temperatures.

Studying the effects that urbanization has on natural systems is the basis for progressive LID design. Careful design by engineers can reduce the human footprint on many threatened ecosystems. This study examines one consequence that is associated with development when it encroaches on cold water stream watersheds. Implementing bioretention on only select developments in a watershed will not solve the problem. The concept of best management practices needs to be applied not to single small scale developments but on a watershed scale. With continuing research, the entire field of low impact development can grow and evolve as complex problems arise that require solutions. 


\section{Bibliography}

[1] Barbis, J. \& Welker, A. L. (2010). Stormwater temperature mitigation beneath porous pavements. World Environmental and Water Resources Congress 2010: Challenges of Change, 3971-3979.

[2] Coutant, C. C. (1977). Compilation of temperature preference data. Journal of the Fisheries Research Board of Canada, 34, 740-745.

[3] Commonwealth of Virginia (2010). "9 VAC 25-260 Virginia Water Quality Standards", State Water Control Board, Statutory Authority: \62.1-44.15 3a of the Code of Virginia.

[4] Davis, A. P., Hunt, W. F., Traver, R. G., \& Clar, M. (2009). Bioretention Technology: Overview of Current Practice and Future Needs. Journal of Environmental Engineering, 135(3), 109-117.

[5] Davis, A. P. (2008). Field Performance of Bioretention: Hydrology Impact. Journal of Hydrologic Engineering, 13(2), 90-95.

[6] Davis, A. P. (2007). Field Performance of Bioretention: Water Quality. Environmental Engineering Science, 24(8), 1048-1063.

[7] DeBusk, K., Wynn, T., \& Yagow, E. (2009). Reducing Urban Stormwater Impacts within the Stroubles Creek Watershed. BSE Document Number 2009-0004. Submitted to the Virginia Department of Conservation and Recreation, Richmond, VA. 65 pp.

[8] Eaton, J. G., McCormick, J. H., Goodno, B. E., et al. (1995). A Field InformationBased System for Estimating Fish Temperature Tolerances. Fisheries, 20(4), 10-18.

[9] Edwards, R. W., Densem, J. W., \& Russell, P. A. (1979). An Assessment of the Importance of Temperature as a Factor Controlling the Growth Rate of Brown Trout in Streams. Journal of Animal Ecology, 48(2), 501-507. 
[10] Herb, W. R., Janke, B., et al. (2009). Runoff Temperature Model for Paved Surfaces. Journal of Hydrologic Engineering, 14(10), 1146-1155.

[11] Herb, W. R., Mohseni, O., \& Stefan, H. G. (2009). Simulation of Temperature Mitigation by a Stormwater Detention Pond. Journal of the American Water Resources Association, 45(5), 1164-1178.

[12] Janke, B. D., Herb, W. R., et al., (2009). Simulation of heat export by rainfall-runoff from a paved surface. Journal of Hydrology, 365 (3-4), 195-212.

[13] Jones, M. P., \& Hunt, W. F. (2009). Bioretention Impact on Runoff Temperature in Trout Sensitive Waters. Joumal of Environmental Engineering, 135(8), 577-585.

[14] Jones, M. P., Hunt, W. F., \& Smith, J. T. (2007). The Effect of Urban Stormwater BMPs on Runoff Temperature in Trout Sensitive Waters. Proceedings of the World Environmental and Water Resources Congress. 243, p. 438. Tampa, FL: ASCE.

[15] Kieser, M. S., Spoelstra, J. A., Feng Feng, A., James, W., \& Li, Y. (2004). Stormwater thermal enrichment in urban watersheds. Water Environment Research Foundation, Alexandria, Va.

[16] Klein, R. D. (1979). Urbanization and Stream Quality Impairment. Journal of the American Water Resources Association, 15(4), 948-963.

[17] Lee, R. M., \& Rinne, J. N. (1980). Critical Thermal Maxima of Five Trout Species in the Southwestern United States. Transactions of the American Fisheries Society, 109, 632635.

[18] Matthews, K. R., Berg, N. H., Azuma, D. L., \& Lambert, T. R. (1994). Cool Water Formation and Trout Habitat Use In a Deep Pool In the Sierra-Nevada, California. Transactions of the American Fisheries Society, 123(4), 549-564.

[19] Matthews, K. R., \& Berg, N. H. (1997). Rainbow trout responses to water temperature and dissolved oxygen stress in two southern California stream pools. Journal of Fish Biology, 50(1), 50-67.

[20] Nelson, K. P., \& Palmer M.A. (2007). Stream temperature surges underurbanization and climate change: Data, models, and responses. Journal of the American Water Resources Association, 43(2), 440-452.

[21] Poole, G. C., \& Berman, C. H. (2001). An Ecological Perspective on In-Stream Temperature: Natural Heat Dynamics and Mechanisms of Human-Caused Thermal Degradation. Environmental Management, 27(6), 787-802 
[22] Prince George's County, MD. (2007). Bioretention Manual. Department of Environmental Resources.

[23] Thompson, A. M., Wilson, T., et al. (2008). Modeling the Effect of Summertime Heating on Urban Runoff Temperature. Journal of the American Water Resources Association, 44(6), 1548-1563.

[24] Thompson, A. M., Kim, K., \& Vandermuss, A. J. (2008). Thermal Characteristics of Stormwater Runoff from Asphalt and Sod Surfaces. Journal of the American Water Resources Association, 44(5), 1325-1336.

[25] Wang, L. H., \& Kanehl, P. (2003). Influences of watershed urbanization and instream habitat on macroinvertebrates in cold water streams. Journal of the American Water Resources Association, 39(5), 1181-1196. 


\section{Appendix A}

This section covers in greater detail the data that was collected during the series of ten trials conducted at the Blacksburg Community Center bioretention facility. Temperature and flow data are shown in thermal pollutographs. It should be noted that the temperature data was averaged for each minute of flow so the peak temperatures referenced in the paper may not exactly correspond with the averaged data in the tables. 


\section{Trial \#1}

Table A.1: Trial \#1 Flow Data

\section{Hydrant}

\begin{tabular}{cccccc}
\hline $\begin{array}{c}\text { Time } \\
\text { (min.) }\end{array}$ & $\begin{array}{c}\text { Flow Rate } \\
\text { (cfs) }\end{array}$ & $\begin{array}{c}\text { Volume } \\
\text { (cu. ft.) }\end{array}$ & $\begin{array}{c}\text { Time } \\
\text { (min.) }\end{array}$ & $\begin{array}{c}\text { Flow Rate } \\
\text { (cfs) }\end{array}$ & $\begin{array}{c}\text { Volume } \\
\text { (cu. ft.) }\end{array}$ \\
\hline 1 & 0.084 & 5.0 & 14 & 0.535 & 404.3 \\
2 & 0.234 & 19.1 & 15 & 0.535 & 436.4 \\
3 & 0.535 & 51.2 & 16 & 0.535 & 468.5 \\
4 & 0.535 & 83.3 & 17 & 0.535 & 500.6 \\
5 & 0.535 & 115.4 & 18 & 0.535 & 532.7 \\
6 & 0.535 & 147.5 & 19 & 0.594 & 568.3 \\
7 & 0.535 & 179.6 & 20 & 0.594 & 604.0 \\
8 & 0.535 & 211.7 & 21 & 0.594 & 639.6 \\
9 & 0.535 & 243.8 & 22 & 0.594 & 675.2 \\
10 & 0.535 & 275.9 & 23 & 0.594 & 710.9 \\
11 & 0.535 & 308.0 & 24 & 0.594 & 746.5 \\
12 & 0.535 & 340.1 & & & \\
13 & 0.535 & 372.2 & & & \\
\hline
\end{tabular}

\section{Outflow}

\begin{tabular}{ccc}
\hline $\begin{array}{c}\text { Time } \\
\text { (min.) }\end{array}$ & $\begin{array}{c}\text { Flow Rate } \\
\text { (cfs) }\end{array}$ & $\begin{array}{c}\text { Volume } \\
\text { (cu. ft. })\end{array}$ \\
\hline 14 & 0 & 0 \\
15 & 0.167 & 5.0 \\
16 & 0.294 & 18.8 \\
19 & 0.428 & 83.8 \\
24 & 0.468 & 218.2 \\
29 & 0.401 & 348.6 \\
34 & 0.361 & 462.9 \\
39 & 0.281 & 559.2 \\
44 & 0.174 & 627.4 \\
49 & 0.134 & 673.6 \\
54 & 0.03 & 698.2 \\
59 & 0.01 & 704.2 \\
74 & 0.003 & 710.1 \\
\hline
\end{tabular}

Figure A.1: 'Trial \#1

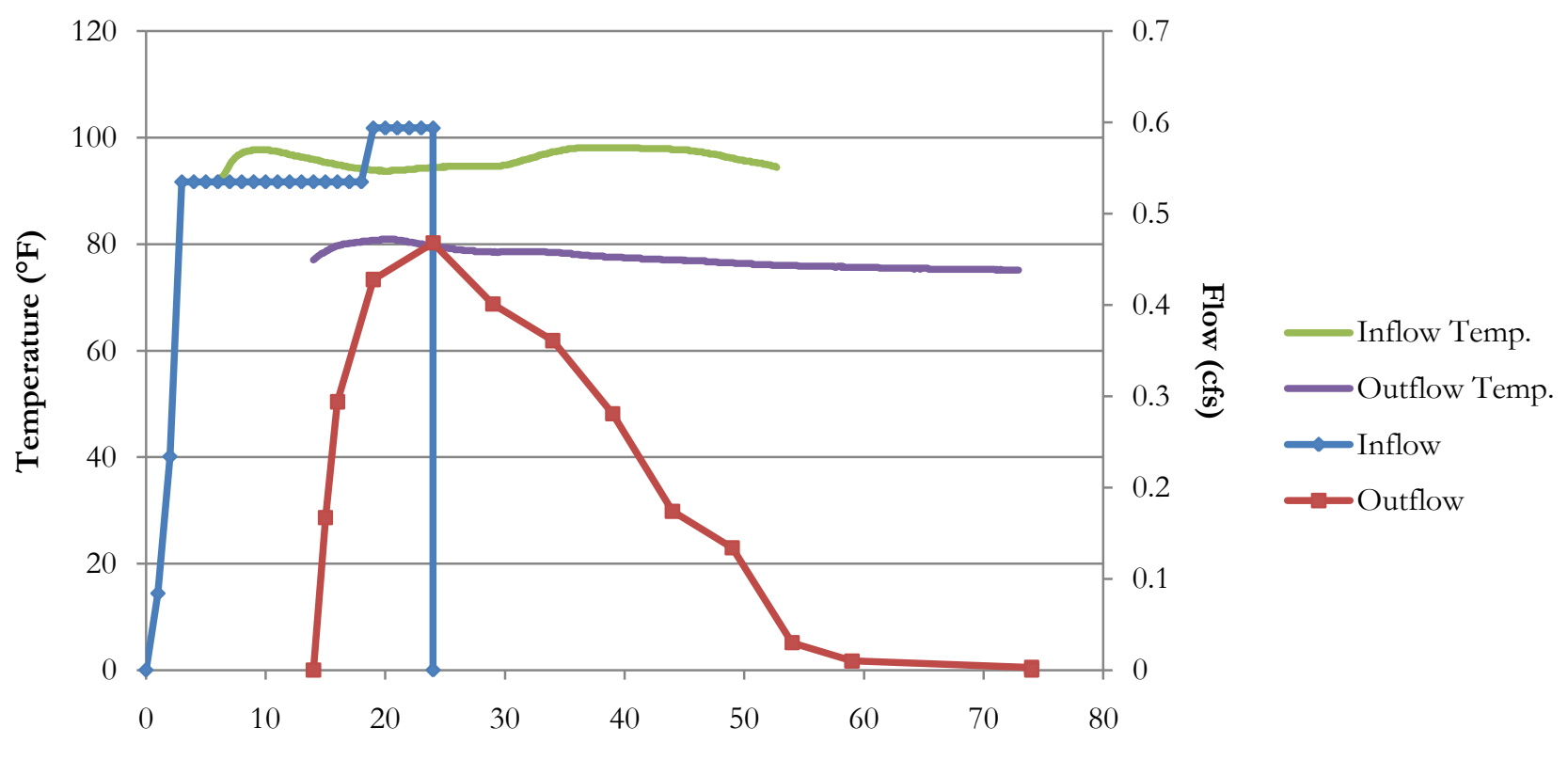

Time (minutes) 
Table A.2: Trial \#1 Temperature Data

Inflow

\begin{tabular}{cccc}
\hline Minute & $\begin{array}{c}\text { Temp. } \\
\left({ }^{\circ} \mathrm{F}\right)\end{array}$ & Minute & $\begin{array}{c}\text { Temp. } \\
\left({ }^{\circ} \mathrm{F}\right)\end{array}$ \\
\hline 6 & 93.1 & 27 & 94.6 \\
7 & 96.1 & 28 & 94.6 \\
8 & 97.4 & 29 & 94.7 \\
9 & 97.7 & 30 & 95.1 \\
10 & 97.6 & 31 & 95.7 \\
11 & 97.2 & 32 & 96.3 \\
12 & 96.6 & 33 & 97.0 \\
13 & 96.2 & 34 & 97.5 \\
14 & 95.7 & 35 & 97.9 \\
15 & 95.2 & 36 & 98.1 \\
16 & 94.7 & 37 & 98.1 \\
17 & 94.3 & 38 & 98.1 \\
18 & 94.0 & 39 & 98.1 \\
19 & 93.8 & 40 & 98.1 \\
20 & 93.8 & 41 & 98.0 \\
21 & 93.9 & 42 & 97.9 \\
22 & 94.1 & 43 & 97.9 \\
23 & 94.3 & 44 & 97.7 \\
24 & 94.5 & 45 & 97.6 \\
25 & 94.6 & 51 & 95.1 \\
26 & 94.6 & 52 & 94.7 \\
\hline
\end{tabular}

\section{Outflow}

\begin{tabular}{cccc}
\hline Minute & $\begin{array}{c}\text { Temp. } \\
\left({ }^{\circ} \mathrm{F}\right)\end{array}$ & Minute & $\begin{array}{c}\text { Temp. } \\
\left({ }^{\circ} \mathrm{F}\right)\end{array}$ \\
\hline 14 & 73.9 & 45 & 83.3 \\
15 & 77.0 & 46 & 83.1 \\
16 & 78.9 & 47 & 83.0 \\
17 & 80.4 & 48 & 83.0 \\
18 & 81.8 & 49 & 83.0 \\
19 & 82.9 & 50 & 83.0 \\
20 & 83.6 & 51 & 82.9 \\
21 & 84.0 & 52 & 82.8 \\
22 & 84.3 & 53 & 82.6 \\
23 & 84.7 & 54 & 82.3 \\
24 & 85.0 & 55 & 82.1 \\
25 & 85.3 & 56 & 82.0 \\
26 & 85.5 & 57 & 81.8 \\
27 & 85.8 & 58 & 81.6 \\
28 & 86.0 & 59 & 81.4 \\
29 & 86.2 & 60 & 81.3 \\
30 & 86.3 & 61 & 81.1 \\
31 & 86.5 & 62 & 81.0 \\
32 & 86.6 & 63 & 80.9 \\
33 & 86.6 & 64 & 80.8 \\
34 & 86.5 & 65 & 80.7 \\
35 & 86.4 & 66 & 80.6 \\
36 & 86.1 & 67 & 80.4 \\
37 & 85.8 & 68 & 80.3 \\
38 & 85.5 & 69 & 80.2 \\
39 & 85.2 & 70 & 80.2 \\
40 & 84.8 & 71 & 80.2 \\
41 & 84.5 & 72 & 80.2 \\
42 & 84.1 & 73 & 80.0 \\
43 & 83.8 & 74 & 80.0 \\
44 & 83.5 & & \\
\hline & & & \\
\hline
\end{tabular}




\section{Trial \#2}

Table A.3: Trial \#2 Flow Data

\begin{tabular}{ccc}
\multicolumn{3}{c}{ Hydrant } \\
\hline $\begin{array}{c}\text { Time } \\
\text { (min.) }\end{array}$ & $\begin{array}{c}\text { Flow Rate } \\
\text { (cfs) }\end{array}$ & $\begin{array}{c}\text { Volume } \\
\text { (cu. ft. })\end{array}$ \\
\hline 1 & 0.201 & 12.1 \\
2 & 0.423 & 37.4 \\
3 & 1.058 & 100.9 \\
4 & 1.058 & 164.4 \\
5 & 1.058 & 227.9 \\
6 & 1.058 & 291.4 \\
7 & 1.058 & 354.8 \\
8 & 1.058 & 418.3 \\
9 & 1.058 & 481.8 \\
10 & 1.058 & 545.3 \\
\hline
\end{tabular}

\begin{tabular}{ccc}
\multicolumn{3}{c}{ Outflow } \\
\hline $\begin{array}{c}\text { Time } \\
\text { (min.) }\end{array}$ & $\begin{array}{c}\text { Flow Rate } \\
\text { (cfs) }\end{array}$ & $\begin{array}{c}\text { Volume } \\
\text { (cu. ft. })\end{array}$ \\
\hline 17 & 0 & 0 \\
18 & 0.067 & 2.0 \\
19 & 0.241 & 11.3 \\
22 & 0.394 & 68.4 \\
27 & 0.468 & 197.7 \\
32 & 0.167 & 293.0 \\
37 & 0.120 & 336.0 \\
42 & 0.074 & 365.1 \\
47 & 0.060 & 385.2 \\
52 & 0.053 & 402.2 \\
57 & 0.042 & 416.4 \\
62 & 0.033 & 427.7 \\
77 & 0.025 & 453.8 \\
\hline
\end{tabular}

Figure A.2: Trial \#2

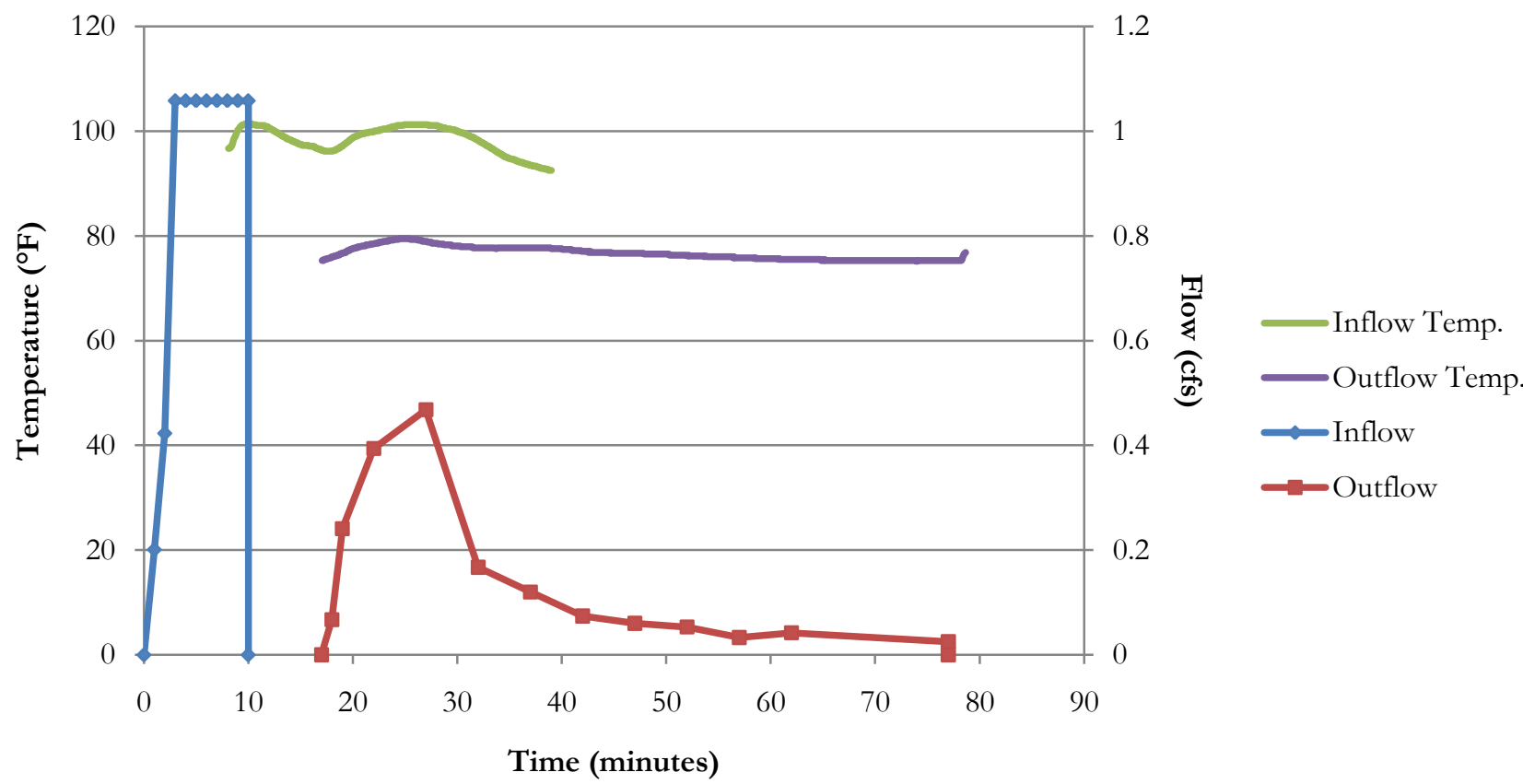


Table A.4: Trial \#2 Temperature Data

\begin{tabular}{|c|c|}
\hline \multicolumn{2}{|c|}{ Inflow } \\
\hline Minute & $\begin{array}{c}\text { Temp. } \\
\left({ }^{\circ} \mathrm{F}\right)\end{array}$ \\
\hline 8 & 98.0 \\
\hline 9 & 101.1 \\
\hline 10 & 101.3 \\
\hline 11 & 101.0 \\
\hline 12 & 100.1 \\
\hline 13 & 98.9 \\
\hline 14 & 97.9 \\
\hline 15 & 97.3 \\
\hline 16 & 96.9 \\
\hline 17 & 96.2 \\
\hline 18 & 96.6 \\
\hline 19 & 97.9 \\
\hline 20 & 99.2 \\
\hline 21 & 99.7 \\
\hline 22 & 100.2 \\
\hline 23 & 100.6 \\
\hline 24 & 101.0 \\
\hline 25 & 101.3 \\
\hline 26 & 101.3 \\
\hline 27 & 101.1 \\
\hline 28 & 100.8 \\
\hline 29 & 100.3 \\
\hline 30 & 99.7 \\
\hline 31 & 98.8 \\
\hline 32 & 97.7 \\
\hline 33 & 96.5 \\
\hline 34 & 95.3 \\
\hline 35 & 94.5 \\
\hline 36 & 93.8 \\
\hline 37 & 93.3 \\
\hline 38 & 92.8 \\
\hline 39 & 92.6 \\
\hline
\end{tabular}

\begin{tabular}{|c|c|c|c|}
\hline \multicolumn{4}{|c|}{ Outflow } \\
\hline Minute & $\begin{array}{c}\text { Temp. } \\
\left({ }^{\circ} \mathrm{F}\right)\end{array}$ & Minute & $\begin{array}{c}\text { Temp. } \\
\left({ }^{\circ} \mathrm{F}\right)\end{array}$ \\
\hline 17 & 75.6 & 49 & 76.5 \\
\hline 18 & 76.3 & 50 & 76.4 \\
\hline 19 & 77.1 & 51 & 76.4 \\
\hline 20 & 77.8 & 52 & 76.2 \\
\hline 21 & 78.3 & 53 & 76.2 \\
\hline 22 & 78.7 & 54 & 76.0 \\
\hline 23 & 79.1 & 55 & 76.0 \\
\hline 24 & 79.4 & 56 & 75.9 \\
\hline 25 & 79.4 & 57 & 75.8 \\
\hline 26 & 79.1 & 58 & 75.8 \\
\hline 27 & 78.8 & 59 & 75.7 \\
\hline 28 & 78.4 & 60 & 75.6 \\
\hline 29 & 78.2 & 61 & 75.5 \\
\hline 30 & 78.0 & 62 & 75.5 \\
\hline 31 & 77.8 & 63 & 75.5 \\
\hline 32 & 77.7 & 64 & 75.5 \\
\hline 33 & 77.7 & 65 & 75.3 \\
\hline 34 & 77.7 & 66 & 75.3 \\
\hline 35 & 77.7 & 67 & 75.3 \\
\hline 36 & 77.7 & 68 & 75.3 \\
\hline 37 & 77.7 & 69 & 75.3 \\
\hline 38 & 77.7 & 70 & 75.3 \\
\hline 39 & 77.6 & 71 & 75.3 \\
\hline 40 & 77.4 & 72 & 75.3 \\
\hline 41 & 77.2 & 73 & 75.3 \\
\hline 42 & 77.0 & 74 & 75.3 \\
\hline 43 & 76.9 & 75 & 75.3 \\
\hline 44 & 76.8 & 76 & 75.3 \\
\hline 45 & 76.7 & 77 & 75.3 \\
\hline 46 & 76.7 & 78 & 75.9 \\
\hline 47 & 76.7 & & \\
\hline 48 & 76.5 & & \\
\hline
\end{tabular}




\section{Trial \#3}

Table A.5: Trial \#3 Flow Data

\begin{tabular}{ccc}
\multicolumn{3}{c}{ Hydrant } \\
\hline $\begin{array}{c}\text { Time } \\
\text { (min.) }\end{array}$ & $\begin{array}{c}\text { Flow Rate } \\
\text { (cfs) }\end{array}$ & $\begin{array}{c}\text { Volume } \\
\text { (cu. ft. })\end{array}$ \\
\hline 1 & 0.290 & 17.4 \\
2 & 0.334 & 37.4 \\
3 & 1.142 & 106.0 \\
4 & 1.142 & 174.5 \\
5 & 1.142 & 243.0 \\
6 & 1.142 & 311.5 \\
7 & 1.142 & 380.0 \\
8 & 1.142 & 448.6 \\
9 & 1.142 & 517.1 \\
10 & 1.142 & 585.6 \\
\hline
\end{tabular}

\begin{tabular}{ccc}
\multicolumn{3}{c}{ Outflow } \\
\hline $\begin{array}{c}\text { Time } \\
\text { (min.) }\end{array}$ & $\begin{array}{c}\text { Flow Rate } \\
\text { (cfs) }\end{array}$ & $\begin{array}{c}\text { Volume } \\
\text { (cu. ft.) }\end{array}$ \\
\hline 13 & 0 & 0 \\
14 & 0.134 & 4.0 \\
15 & 0.187 & 13.7 \\
18 & 0.414 & 67.7 \\
23 & 0.455 & 198.1 \\
28 & 0.307 & 312.4 \\
33 & 0.147 & 380.5 \\
38 & 0.100 & 417.5 \\
43 & 0.070 & 443.0 \\
48 & 0.043 & 460.0 \\
53 & 0.033 & 471.4 \\
58 & 0.027 & 480.4 \\
73 & 0.013 & 498.4 \\
\hline
\end{tabular}

Figure A.3: Trial \#3

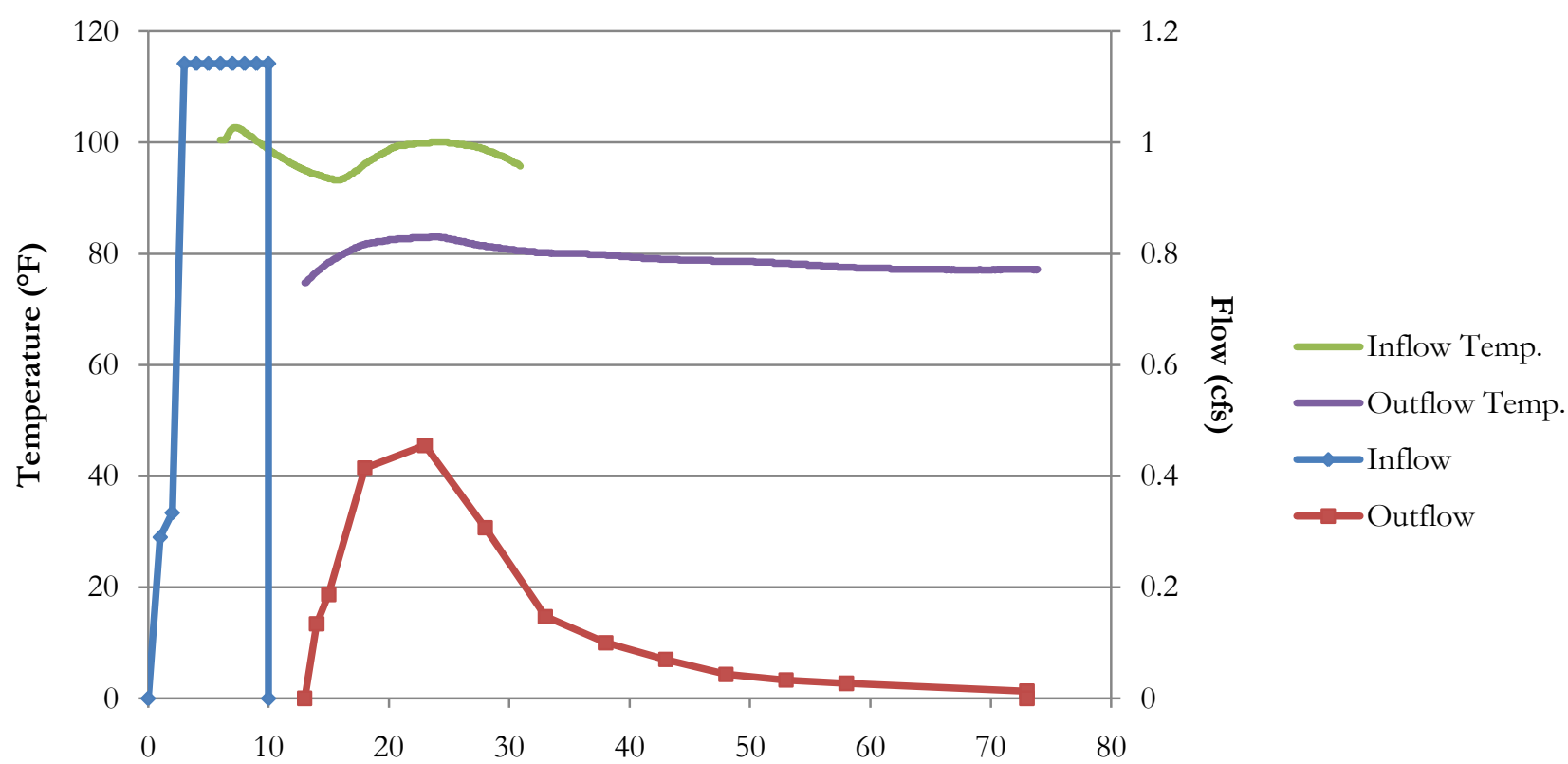

Time (minutes) 


\section{Table A.6: Trial \#3 Temperature Data}

\begin{tabular}{cc}
\multicolumn{2}{c}{ Inflow } \\
\hline Minute & $\begin{array}{c}\text { Temp. } \\
\left({ }^{\circ} \mathrm{F}\right)\end{array}$ \\
\hline 6 & 101.1 \\
7 & 102.5 \\
8 & 101.2 \\
9 & 99.6 \\
10 & 98.1 \\
11 & 96.8 \\
12 & 95.6 \\
13 & 94.7 \\
14 & 93.9 \\
15 & 93.4 \\
16 & 93.8 \\
17 & 95.2 \\
18 & 96.7 \\
19 & 98.0 \\
20 & 99.1 \\
21 & 99.6 \\
22 & 99.8 \\
23 & 100.0 \\
24 & 100.1 \\
25 & 99.8 \\
26 & 99.5 \\
27 & 99.1 \\
28 & 98.3 \\
29 & 97.5 \\
30 & 96.4 \\
\hline & \\
& \\
& \\
& \\
16 &
\end{tabular}

\section{Outflow}

\begin{tabular}{|c|c|c|c|}
\hline Minute & $\begin{array}{c}\text { Temp. } \\
\left({ }^{\circ} \mathrm{F}\right)\end{array}$ & Minute & $\begin{array}{c}\text { Temp. } \\
\left({ }^{\circ} \mathrm{F}\right)\end{array}$ \\
\hline 13 & 75.6 & 44 & 78.8 \\
\hline 14 & 77.5 & 45 & 78.8 \\
\hline 15 & 79.0 & 46 & 78.8 \\
\hline 16 & 80.2 & 47 & 78.6 \\
\hline 17 & 81.2 & 48 & 78.6 \\
\hline 18 & 81.9 & 49 & 78.6 \\
\hline 19 & 82.2 & 50 & 78.5 \\
\hline 20 & 82.6 & 51 & 78.4 \\
\hline 21 & 82.7 & 52 & 78.3 \\
\hline 22 & 82.9 & 53 & 78.2 \\
\hline 23 & 83.0 & 54 & 78.1 \\
\hline 24 & 82.9 & 55 & 77.9 \\
\hline 25 & 82.5 & 56 & 77.7 \\
\hline 26 & 82.0 & 57 & 77.6 \\
\hline 27 & 81.5 & 58 & 77.5 \\
\hline 28 & 81.2 & 59 & 77.4 \\
\hline 29 & 80.9 & 60 & 77.4 \\
\hline 30 & 80.6 & 61 & 77.3 \\
\hline 31 & 80.5 & 62 & 77.2 \\
\hline 32 & 80.2 & 63 & 77.2 \\
\hline 33 & 80.1 & 64 & 77.2 \\
\hline 34 & 80.0 & 65 & 77.2 \\
\hline 35 & 80.0 & 66 & 77.2 \\
\hline 36 & 80.0 & 67 & 77.1 \\
\hline 37 & 79.9 & 68 & 77.1 \\
\hline 38 & 79.7 & 69 & 77.1 \\
\hline 39 & 79.5 & 70 & 77.1 \\
\hline 40 & 79.3 & 71 & 77.2 \\
\hline 41 & 79.2 & 72 & 77.2 \\
\hline 42 & 79.1 & 73 & 77.2 \\
\hline 43 & 79.0 & & \\
\hline
\end{tabular}




\section{Trial \#4}

Table A.7: Trial \#4 Flow Data

\begin{tabular}{ccc}
\multicolumn{3}{c}{ Hydrant } \\
\hline $\begin{array}{c}\text { Time } \\
\text { (min.) }\end{array}$ & $\begin{array}{c}\text { Flow Rate } \\
(\mathrm{cfs})\end{array}$ & $\begin{array}{c}\text { Volume } \\
(\text { cu. ft. })\end{array}$ \\
\hline 1 & 0.098 & 5.9 \\
2 & 0.334 & 25.9 \\
3 & 0.865 & 77.8 \\
4 & 0.865 & 129.7 \\
5 & 0.865 & 181.6 \\
6 & 0.865 & 233.5 \\
7 & 0.865 & 285.4 \\
8 & 0.865 & 337.3 \\
9 & 0.865 & 389.2 \\
10 & 0.865 & 441.1 \\
\hline
\end{tabular}

\begin{tabular}{ccc}
\multicolumn{3}{c}{ Outflow } \\
\hline $\begin{array}{c}\text { Time } \\
\text { (min.) }\end{array}$ & $\begin{array}{c}\text { Flow Rate } \\
\text { (cfs) }\end{array}$ & $\begin{array}{c}\text { Volume } \\
\text { (cu. ft.) }\end{array}$ \\
\hline 14 & 0 & 0 \\
15 & 0.12 & 3.6 \\
16 & 0.227 & 14.0 \\
19 & 0.455 & 75.4 \\
24 & 0.348 & 195.8 \\
29 & 0.201 & 278.2 \\
34 & 0.16 & 332.3 \\
39 & 0.08 & 368.3 \\
44 & 0.05 & 387.8 \\
49 & 0.037 & 400.9 \\
54 & 0.023 & 409.9 \\
59 & 0.015 & 415.6 \\
74 & 0.01 & 426.8 \\
\hline
\end{tabular}

Figure A.4: Trial \#4

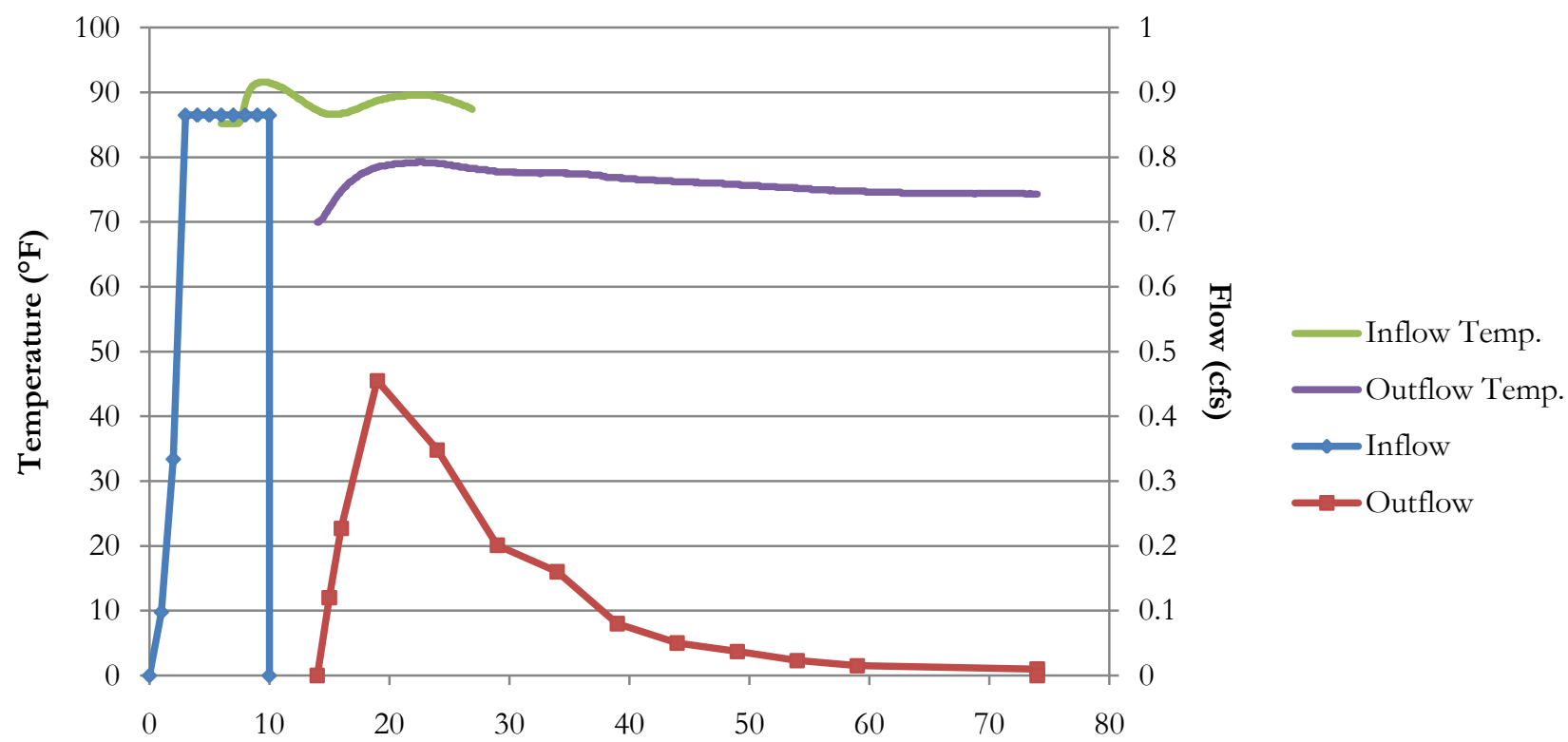

Time (minutes) 
Table A.8: Run \#4 Temperature Data

\begin{tabular}{cc}
\multicolumn{2}{c}{ Inflow } \\
\hline Minute & $\begin{array}{c}\text { Temp. } \\
\left({ }^{\circ} \mathrm{F}\right)\end{array}$ \\
\hline 6 & 85.2 \\
7 & 85.8 \\
8 & 90.3 \\
9 & 91.6 \\
10 & 91.2 \\
11 & 90.3 \\
12 & 89.1 \\
13 & 87.8 \\
14 & 86.9 \\
15 & 86.6 \\
16 & 86.9 \\
17 & 87.6 \\
18 & 88.3 \\
19 & 88.9 \\
20 & 89.3 \\
21 & 89.5 \\
22 & 89.6 \\
23 & 89.5 \\
24 & 89.1 \\
25 & 88.5 \\
26 & 87.8 \\
\hline
\end{tabular}

\section{Outflow}

\begin{tabular}{|c|c|c|c|}
\hline Minute & $\begin{array}{c}\text { Temp. } \\
\left({ }^{\circ} \mathrm{F}\right)\end{array}$ & Minute & $\begin{array}{c}\text { Temp. } \\
\left({ }^{\circ} \mathrm{F}\right)\end{array}$ \\
\hline 14 & 70.7 & 45 & 76.1 \\
\hline 15 & 73.4 & 46 & 76.0 \\
\hline 16 & 75.6 & 47 & 76.0 \\
\hline 17 & 77.1 & 48 & 75.8 \\
\hline 18 & 78.1 & 49 & 75.7 \\
\hline 19 & 78.6 & 50 & 75.6 \\
\hline 20 & 78.9 & 51 & 75.5 \\
\hline 21 & 79.1 & 52 & 75.4 \\
\hline 22 & 79.2 & 53 & 75.3 \\
\hline 23 & 79.2 & 54 & 75.1 \\
\hline 24 & 78.9 & 55 & 75.0 \\
\hline 25 & 78.7 & 56 & 74.9 \\
\hline 26 & 78.4 & 57 & 74.8 \\
\hline 27 & 78.2 & 58 & 74.8 \\
\hline 28 & 77.9 & 59 & 74.7 \\
\hline 29 & 77.7 & 60 & 74.6 \\
\hline 30 & 77.7 & 61 & 74.6 \\
\hline 31 & 77.6 & 62 & 74.6 \\
\hline 32 & 77.6 & 63 & 74.4 \\
\hline 33 & 77.6 & 64 & 74.4 \\
\hline 34 & 77.5 & 65 & 74.4 \\
\hline 35 & 77.4 & 66 & 74.4 \\
\hline 36 & 77.3 & 67 & 74.4 \\
\hline 37 & 77.2 & 68 & 74.4 \\
\hline 38 & 76.9 & 69 & 74.4 \\
\hline 39 & 76.8 & 70 & 74.4 \\
\hline 40 & 76.6 & 71 & 74.4 \\
\hline 41 & 76.5 & 72 & 74.4 \\
\hline 42 & 76.4 & 73 & 74.3 \\
\hline 43 & 76.3 & 74 & 74.3 \\
\hline 44 & 76.2 & & \\
\hline
\end{tabular}




\section{Trial \#5}

Table A.9: Trial \#5 Flow Data

\begin{tabular}{ccc}
\multicolumn{3}{c}{ Hydrant } \\
\hline $\begin{array}{c}\text { Time } \\
\text { (min.) }\end{array}$ & $\begin{array}{c}\text { Flow Rate } \\
\text { (cfs) }\end{array}$ & $\begin{array}{c}\text { Volume } \\
\text { (cu. ft. })\end{array}$ \\
\hline 1 & 0.223 & 13.4 \\
2 & 0.668 & 53.5 \\
3 & 0.863 & 105.2 \\
4 & 0.863 & 157.0 \\
5 & 0.863 & 208.8 \\
6 & 0.863 & 260.6 \\
7 & 0.863 & 312.4 \\
8 & 0.863 & 364.1 \\
9 & 0.863 & 415.9 \\
10 & 0.863 & 467.7 \\
\hline
\end{tabular}

\begin{tabular}{ccc}
\multicolumn{3}{c}{ Outflow } \\
\hline $\begin{array}{c}\text { Time } \\
\text { (min.) }\end{array}$ & $\begin{array}{c}\text { Flow Rate } \\
\text { (cfs) }\end{array}$ & $\begin{array}{c}\text { Volume } \\
\text { (cu. ft. })\end{array}$ \\
\hline 13 & 0 & 0 \\
14 & 0.16 & 4.8 \\
15 & 0.267 & 17.6 \\
18 & 0.414 & 78.9 \\
23 & 0.341 & 192.2 \\
28 & 0.201 & 273.5 \\
33 & 0.134 & 323.7 \\
38 & 0.067 & 353.9 \\
43 & 0.04 & 369.9 \\
48 & 0.027 & 380.0 \\
53 & 0.018 & 386.7 \\
58 & 0.017 & 392.0 \\
73 & 0.01 & 404.1 \\
\hline
\end{tabular}

Figure A.5: Trial \#5

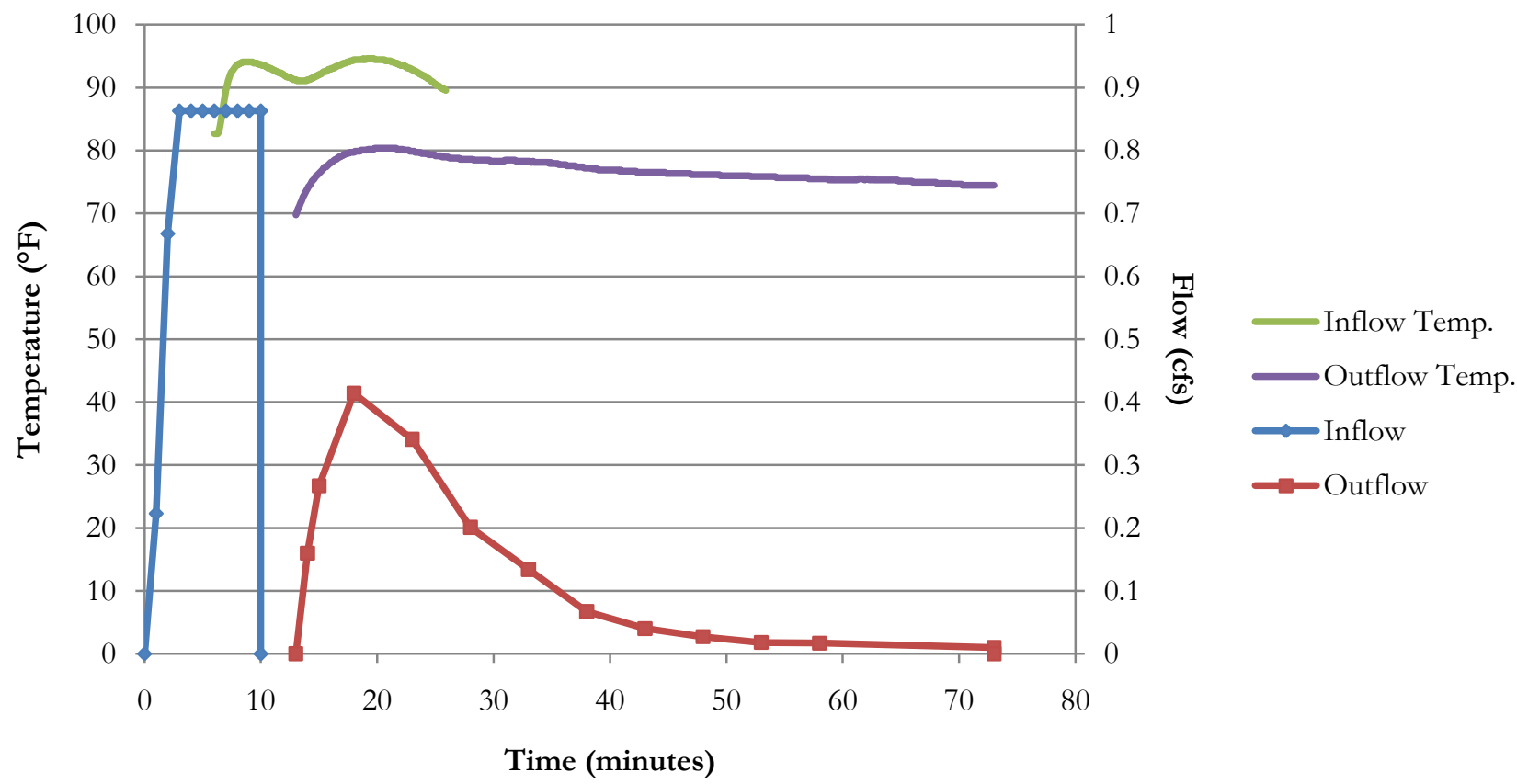


Table A.10: Trial \#5 Temperature Data

\begin{tabular}{cc}
\multicolumn{2}{c}{ Inflow } \\
\hline Minute & $\begin{array}{r}\text { Temp. } \\
\left({ }^{\circ} \mathrm{F}\right)\end{array}$ \\
\hline 6 & 84.5 \\
7 & 92.0 \\
8 & 93.9 \\
9 & 93.9 \\
10 & 93.3 \\
11 & 92.5 \\
12 & 91.6 \\
13 & 91.1 \\
14 & 91.5 \\
15 & 92.5 \\
16 & 93.3 \\
17 & 94.0 \\
18 & 94.5 \\
19 & 94.6 \\
20 & 94.4 \\
21 & 94.0 \\
22 & 93.3 \\
23 & 92.4 \\
24 & 91.3 \\
25 & 90.1 \\
\hline
\end{tabular}

\section{Outflow}

\begin{tabular}{|c|c|c|c|}
\hline Minute & $\begin{array}{c}\text { Temp. } \\
\left({ }^{\circ} \mathrm{F}\right)\end{array}$ & Minute & $\begin{array}{c}\text { Temp. } \\
\left({ }^{\circ} \mathrm{F}\right)\end{array}$ \\
\hline 13 & 71.8 & 44 & 76.5 \\
\hline 14 & 75.1 & 45 & 76.4 \\
\hline 15 & 77.2 & 46 & 76.4 \\
\hline 16 & 78.6 & 47 & 76.2 \\
\hline 17 & 79.5 & 48 & 76.2 \\
\hline 18 & 79.9 & 49 & 76.1 \\
\hline 19 & 80.2 & 50 & 76.0 \\
\hline 20 & 80.4 & 51 & 76.0 \\
\hline 21 & 80.3 & 52 & 75.8 \\
\hline 22 & 80.0 & 53 & 75.8 \\
\hline 23 & 79.7 & 54 & 75.7 \\
\hline 24 & 79.4 & 55 & 75.7 \\
\hline 25 & 79.1 & 56 & 75.7 \\
\hline 26 & 78.8 & 57 & 75.5 \\
\hline 27 & 78.6 & 58 & 75.5 \\
\hline 28 & 78.5 & 59 & 75.3 \\
\hline 29 & 78.4 & 60 & 75.3 \\
\hline 30 & 78.3 & 61 & 75.4 \\
\hline 31 & 78.4 & 62 & 75.4 \\
\hline 32 & 78.3 & 63 & 75.3 \\
\hline 33 & 78.2 & 64 & 75.3 \\
\hline 34 & 78.1 & 65 & 75.1 \\
\hline 35 & 77.9 & 66 & 75.0 \\
\hline 36 & 77.6 & 67 & 75.0 \\
\hline 37 & 77.4 & 68 & 74.8 \\
\hline 38 & 77.1 & 69 & 74.7 \\
\hline 39 & 76.9 & 70 & 74.5 \\
\hline 40 & 76.9 & 71 & 74.4 \\
\hline 41 & 76.7 & 72 & 74.4 \\
\hline 42 & 76.6 & 73 & 74.4 \\
\hline 43 & 76.5 & & \\
\hline
\end{tabular}




\section{Trial \#6}

Table A.11: Trial \#6 Flow Data

\begin{tabular}{ccc}
\multicolumn{3}{c}{ Hydrant } \\
\hline $\begin{array}{c}\text { Time } \\
(\mathrm{min})\end{array}$ & $\begin{array}{c}\text { Flow Rate } \\
\text { (cfs) }\end{array}$ & $\begin{array}{c}\text { Volume } \\
\text { (cu. ft. })\end{array}$ \\
\hline 1 & 0.200 & 12.0 \\
2 & 0.457 & 39.4 \\
3 & 0.746 & 84.2 \\
4 & 0.746 & 128.9 \\
5 & 0.746 & 173.7 \\
6 & 0.746 & 218.5 \\
7 & 0.746 & 263.2 \\
8 & 0.746 & 308.0 \\
9 & 0.746 & 352.7 \\
\hline
\end{tabular}

\begin{tabular}{ccc}
\multicolumn{3}{c}{ Outflow } \\
\hline $\begin{array}{c}\text { Time } \\
\text { (min.) }\end{array}$ & $\begin{array}{c}\text { Flow Rate } \\
\text { (cfs) }\end{array}$ & $\begin{array}{c}\text { Volume } \\
\text { (cu. ft.) }\end{array}$ \\
\hline 13 & 0 & 0 \\
14 & 0.067 & 2.0 \\
15 & 0.100 & 7.0 \\
18 & 0.241 & 37.7 \\
23 & 0.287 & 116.9 \\
28 & 0.180 & 187.0 \\
33 & 0.134 & 234.1 \\
38 & 0.093 & 268.1 \\
43 & 0.067 & 292.1 \\
48 & 0.047 & 309.2 \\
53 & 0.032 & 321.1 \\
58 & 0.023 & 329.3 \\
73 & 0.013 & 345.5 \\
\hline
\end{tabular}

Figure A.6: Trial \#6

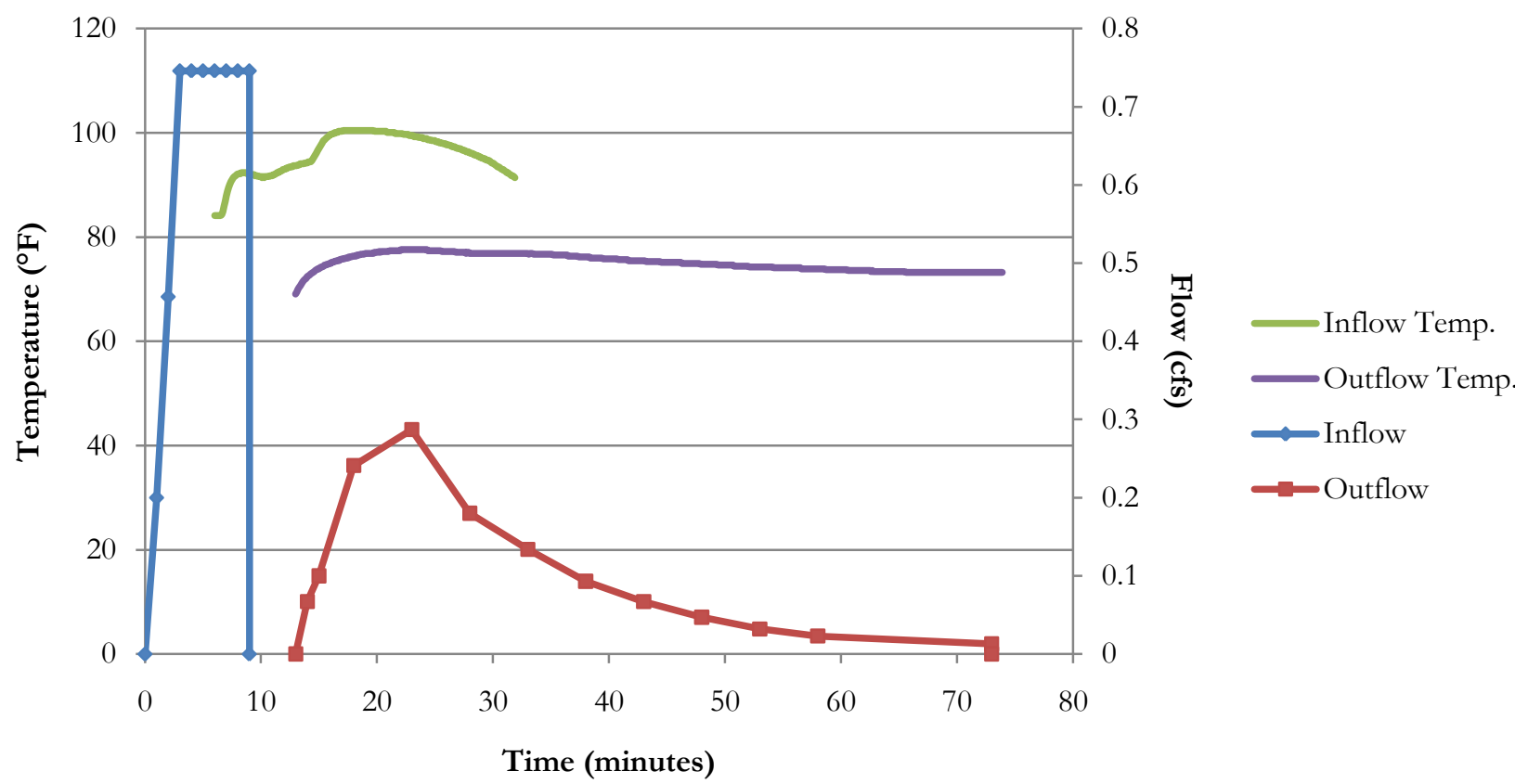


Trial A.12: Trial \#6 Temperature Data

\begin{tabular}{|c|c|}
\hline \multicolumn{2}{|c|}{ Inflow } \\
\hline Minute & $\begin{array}{c}\text { Temp. } \\
\left({ }^{\circ} \mathrm{F}\right)\end{array}$ \\
\hline 6 & 84.7 \\
\hline 7 & 90.5 \\
\hline 8 & 92.3 \\
\hline 9 & 91.9 \\
\hline 10 & 91.6 \\
\hline 11 & 92.3 \\
\hline 12 & 93.4 \\
\hline 13 & 94.0 \\
\hline 14 & 95.1 \\
\hline 15 & 98.4 \\
\hline 16 & 100.0 \\
\hline 17 & 100.5 \\
\hline 18 & 100.5 \\
\hline 19 & 100.4 \\
\hline 20 & 100.3 \\
\hline 21 & 100.0 \\
\hline 22 & 99.7 \\
\hline 23 & 99.3 \\
\hline 24 & 98.7 \\
\hline 25 & 98.2 \\
\hline 26 & 97.4 \\
\hline 27 & 96.7 \\
\hline 28 & 95.8 \\
\hline 29 & 94.8 \\
\hline 30 & 93.5 \\
\hline 31 & 92.1 \\
\hline
\end{tabular}

\section{Outflow}

\begin{tabular}{|c|c|c|c|}
\hline Minute & $\begin{array}{l}\text { Temp. } \\
\left({ }^{\circ} \mathrm{F}\right)\end{array}$ & Minute & $\begin{array}{c}\text { Temp } \\
\left({ }^{\circ} \mathrm{F}\right)\end{array}$ \\
\hline 13 & 70.7 & 44 & 75.2 \\
\hline 14 & 73.1 & 45 & 75.1 \\
\hline 15 & 74.5 & 46 & 75.0 \\
\hline 16 & 75.4 & 47 & 74.9 \\
\hline 17 & 76.0 & 48 & 74.8 \\
\hline 18 & 76.5 & 49 & 74.7 \\
\hline 19 & 76.9 & 50 & 74.6 \\
\hline 20 & 77.2 & 51 & 74.4 \\
\hline 21 & 77.4 & 52 & 74.3 \\
\hline 22 & 77.6 & 53 & 74.3 \\
\hline 23 & 77.6 & 54 & 74.1 \\
\hline 24 & 77.5 & 55 & 74.1 \\
\hline 25 & 77.3 & 56 & 74.0 \\
\hline 26 & 77.2 & 57 & 73.9 \\
\hline 27 & 77.0 & 58 & 73.9 \\
\hline 28 & 76.9 & 59 & 73.8 \\
\hline 29 & 76.9 & 60 & 73.7 \\
\hline 30 & 76.9 & 61 & 73.6 \\
\hline 31 & 76.9 & 62 & 73.5 \\
\hline 32 & 76.9 & 63 & 73.4 \\
\hline 33 & 76.8 & 64 & 73.4 \\
\hline 34 & 76.7 & 65 & 73.3 \\
\hline 35 & 76.6 & 66 & 73.2 \\
\hline 36 & 76.4 & 67 & 73.2 \\
\hline 37 & 76.3 & 68 & 73.2 \\
\hline 38 & 76.1 & 69 & 73.2 \\
\hline 39 & 75.9 & 70 & 73.2 \\
\hline 40 & 75.8 & 71 & 73.2 \\
\hline 41 & 75.6 & 72 & 73.2 \\
\hline 42 & 75.5 & 73 & 73.2 \\
\hline 43 & 75.3 & & \\
\hline
\end{tabular}




\section{Trial \#7}

Table A.13: Trial \#7 Flow Data

\begin{tabular}{ccc}
\multicolumn{3}{c}{ Hydrant } \\
\hline $\begin{array}{c}\text { Time } \\
(\text { min. })\end{array}$ & $\begin{array}{c}\text { Flow Rate } \\
(\mathrm{cfs})\end{array}$ & $\begin{array}{c}\text { Volume } \\
(\mathrm{cu} . \mathrm{ft})\end{array}$ \\
\hline 1 & 0.263 & 15.8 \\
2 & 0.401 & 39.8 \\
3 & 0.808 & 88.3 \\
4 & 0.808 & 136.8 \\
5 & 0.808 & 185.3 \\
6 & 0.808 & 233.8 \\
7 & 0.808 & 282.2 \\
8 & 0.808 & 330.7 \\
9 & 0.808 & 379.2 \\
10 & 0.808 & 427.7 \\
\hline
\end{tabular}

\begin{tabular}{ccc} 
Outflow \\
\hline $\begin{array}{c}\text { Time } \\
\text { (min.) }\end{array}$ & $\begin{array}{c}\text { Flow Rate } \\
\text { (cfs) }\end{array}$ & $\begin{array}{c}\text { Volume } \\
\text { (cu. ft) }\end{array}$ \\
\hline 13 & 0 & 0 \\
14 & 0.120 & 3.6 \\
15 & 0.214 & 13.6 \\
18 & 0.361 & 65.4 \\
23 & 0.388 & 177.7 \\
28 & 0.180 & 262.9 \\
33 & 0.134 & 310.0 \\
38 & 0.107 & 346.2 \\
43 & 0.047 & 369.3 \\
48 & 0.037 & 381.9 \\
53 & 0.032 & 392.2 \\
58 & 0.017 & 399.6 \\
73 & 0.010 & 411.7 \\
\hline
\end{tabular}

Figure A.7: $\quad$ Trial \#7

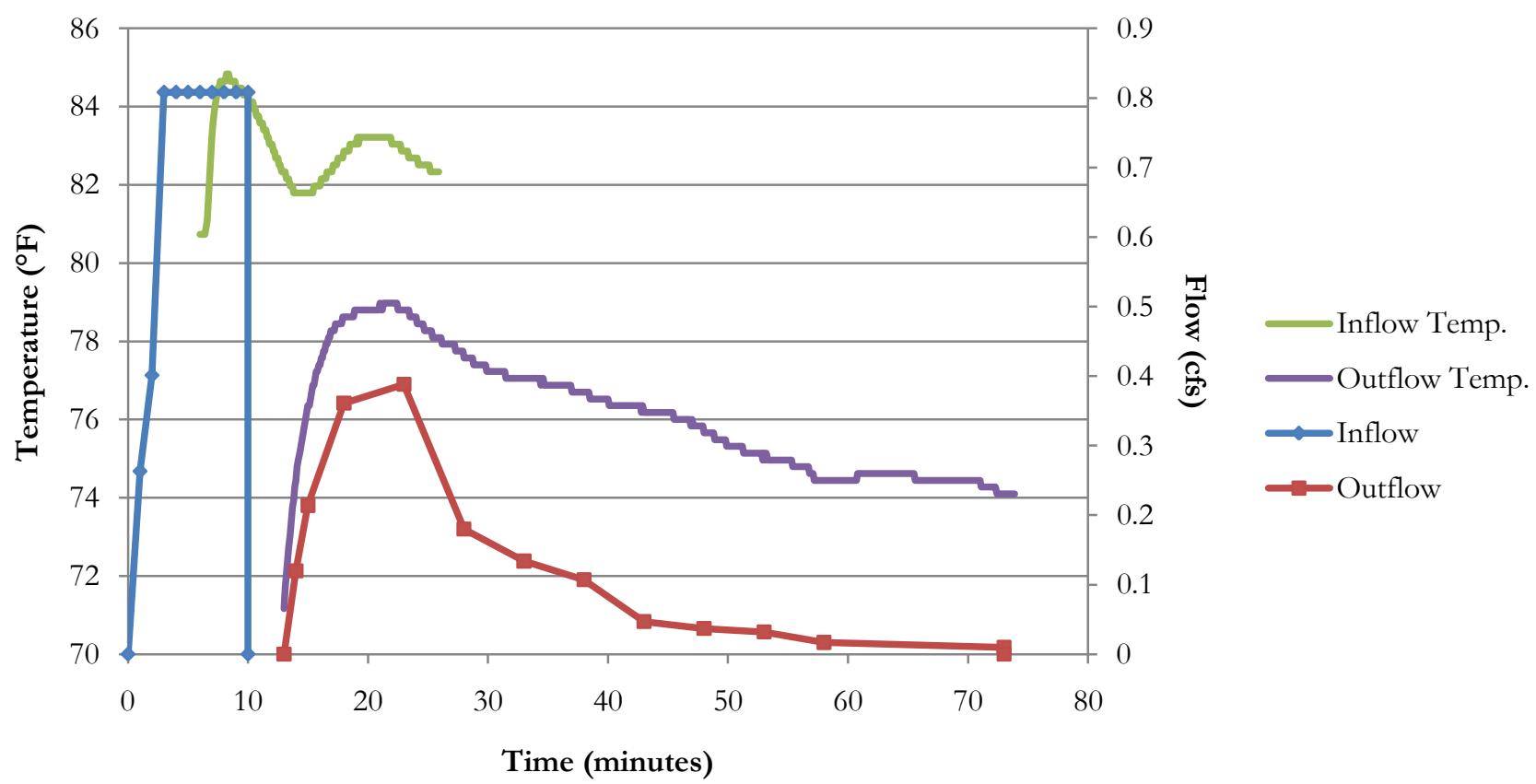


Table A.14: Trial \#7 Temperature Data

\begin{tabular}{cc}
\multicolumn{2}{c}{ Inflow } \\
\hline Minute & $\begin{array}{r}\text { Temp. } \\
\left({ }^{\circ} \mathrm{F}\right)\end{array}$ \\
\hline 6 & 81.2 \\
7 & 84.2 \\
8 & 84.7 \\
9 & 84.4 \\
10 & 84.0 \\
11 & 83.3 \\
12 & 82.7 \\
13 & 82.1 \\
14 & 81.8 \\
15 & 81.9 \\
16 & 82.2 \\
17 & 82.6 \\
18 & 83.0 \\
19 & 83.2 \\
20 & 83.2 \\
21 & 83.2 \\
22 & 83.0 \\
23 & 82.8 \\
24 & 82.5 \\
25 & 82.4 \\
\hline
\end{tabular}

\section{Outflow}

\begin{tabular}{|c|c|c|c|}
\hline Minute & $\begin{array}{c}\text { Temp. } \\
\left({ }^{\circ} \mathrm{F}\right)\end{array}$ & Minute & $\begin{array}{c}\text { Temp } \\
\left({ }^{\circ} \mathrm{F}\right)\end{array}$ \\
\hline 13 & 72.8 & 44 & 76.2 \\
\hline 14 & 75.4 & 45 & 76.1 \\
\hline 15 & 76.9 & 46 & 76.0 \\
\hline 16 & 77.8 & 47 & 75.8 \\
\hline 17 & 78.4 & 48 & 75.6 \\
\hline 18 & 78.6 & 49 & 75.5 \\
\hline 19 & 78.8 & 50 & 75.3 \\
\hline 20 & 78.8 & 51 & 75.2 \\
\hline 21 & 78.9 & 52 & 75.1 \\
\hline 22 & 78.9 & 53 & 75.0 \\
\hline 23 & 78.7 & 54 & 75.0 \\
\hline 24 & 78.4 & 55 & 74.9 \\
\hline 25 & 78.2 & 56 & 74.8 \\
\hline 26 & 78.0 & 57 & 74.5 \\
\hline 27 & 77.8 & 58 & 74.4 \\
\hline 28 & 77.5 & 59 & 74.4 \\
\hline 29 & 77.4 & 60 & 74.5 \\
\hline 30 & 77.2 & 61 & 74.6 \\
\hline 31 & 77.1 & 62 & 74.6 \\
\hline 32 & 77.1 & 63 & 74.6 \\
\hline 33 & 77.1 & 64 & 74.6 \\
\hline 34 & 77.0 & 65 & 74.5 \\
\hline 35 & 76.9 & 66 & 74.4 \\
\hline 36 & 76.9 & 67 & 74.4 \\
\hline 37 & 76.7 & 68 & 74.4 \\
\hline 38 & 76.6 & 69 & 74.4 \\
\hline 39 & 76.5 & 70 & 74.4 \\
\hline 40 & 76.4 & 71 & 74.3 \\
\hline 41 & 76.4 & 72 & 74.2 \\
\hline 42 & 76.3 & 73 & 74.1 \\
\hline 43 & 76.2 & & \\
\hline
\end{tabular}




\section{Trial \#8}

Table A.15: Trial \#8 Flow Data

\begin{tabular}{ccc}
\multicolumn{3}{c}{ Hydrant } \\
\hline $\begin{array}{c}\text { Time } \\
\text { (min.) }\end{array}$ & $\begin{array}{c}\text { Flow Rate } \\
\text { (cfs) }\end{array}$ & $\begin{array}{c}\text { Volume } \\
\text { (cu. ft. })\end{array}$ \\
\hline 1 & 0.223 & 13.4 \\
2 & 0.668 & 53.5 \\
3 & 0.891 & 106.9 \\
4 & 0.891 & 160.4 \\
5 & 0.891 & 213.9 \\
6 & 0.891 & 267.4 \\
7 & 0.891 & 320.8 \\
8 & 0.891 & 374.3 \\
9 & 0.891 & 427.8 \\
10 & 0.891 & 481.3 \\
\hline
\end{tabular}

\begin{tabular}{ccc}
\multicolumn{3}{c}{ Outflow } \\
\hline $\begin{array}{c}\text { Time } \\
\text { (min.) }\end{array}$ & $\begin{array}{c}\text { Flow Rate } \\
\text { (cfs) }\end{array}$ & $\begin{array}{c}\text { Volume } \\
\text { (cu. ft.) }\end{array}$ \\
\hline 12 & 0 & 0 \\
13 & 0.167 & 5.0 \\
14 & 0.254 & 17.6 \\
17 & 0.401 & 76.6 \\
22 & 0.428 & 200.9 \\
27 & 0.287 & 308.2 \\
32 & 0.140 & 372.2 \\
37 & 0.067 & 403.3 \\
42 & 0.050 & 420.8 \\
47 & 0.030 & 432.8 \\
52 & 0.018 & 440.0 \\
57 & 0.015 & 445.0 \\
72 & 0.008 & 455.3 \\
\hline
\end{tabular}

Figure A.8: $\quad$ Trial \#8

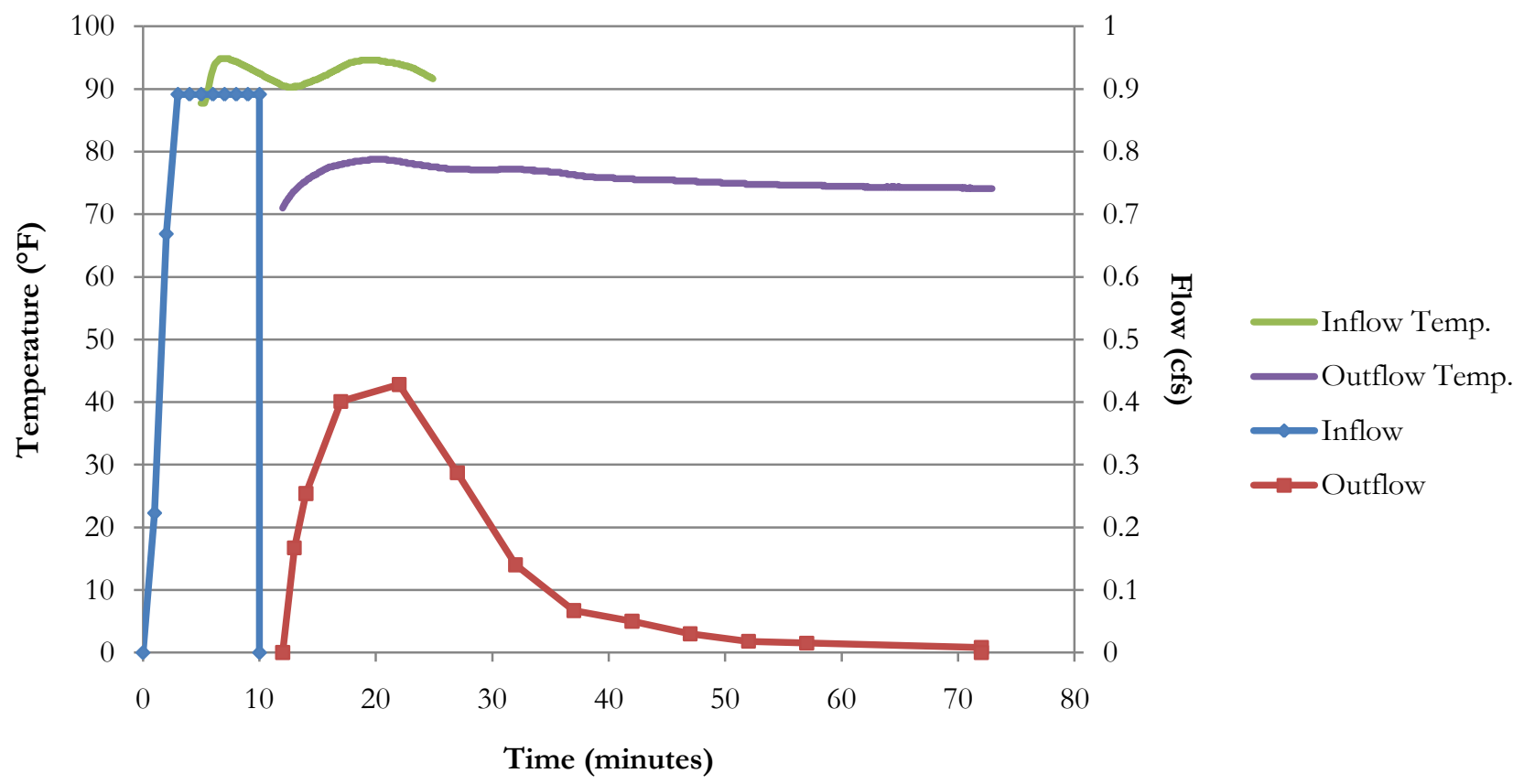


Table A.16: Trial \#8 Temperature Data

\begin{tabular}{cc}
\multicolumn{2}{c}{ Inflow } \\
\hline Minute & $\begin{array}{c}\text { Temp. } \\
\left({ }^{\circ} \mathrm{F}\right)\end{array}$ \\
\hline 5 & 89.3 \\
6 & 94.3 \\
7 & 94.7 \\
8 & 94.0 \\
9 & 93.0 \\
10 & 92.0 \\
11 & 91.1 \\
12 & 90.4 \\
13 & 90.6 \\
14 & 91.2 \\
15 & 92.0 \\
16 & 92.9 \\
17 & 93.9 \\
18 & 94.5 \\
19 & 94.6 \\
20 & 94.5 \\
21 & 94.2 \\
22 & 93.7 \\
23 & 93.1 \\
24 & 92.1 \\
\hline &
\end{tabular}

\section{Outflow}

\begin{tabular}{|c|c|c|c|}
\hline Minute & $\begin{array}{l}\text { Temp. } \\
\left({ }^{\circ} \mathrm{F}\right)\end{array}$ & Minute & $\begin{array}{c}\text { Temp. } \\
\left({ }^{\circ} \mathrm{F}\right)\end{array}$ \\
\hline 12 & 72.3 & 43 & 75.5 \\
\hline 13 & 74.5 & 44 & 75.5 \\
\hline 14 & 75.9 & 45 & 75.4 \\
\hline 15 & 77.0 & 46 & 75.3 \\
\hline 16 & 77.7 & 47 & 75.2 \\
\hline 17 & 78.1 & 48 & 75.1 \\
\hline 18 & 78.4 & 49 & 75.1 \\
\hline 19 & 78.7 & 50 & 75.0 \\
\hline 20 & 78.8 & 51 & 74.9 \\
\hline 21 & 78.6 & 52 & 74.8 \\
\hline 22 & 78.3 & 53 & 74.8 \\
\hline 23 & 78.0 & 54 & 74.7 \\
\hline 24 & 77.7 & 55 & 74.6 \\
\hline 25 & 77.5 & 56 & 74.6 \\
\hline 26 & 77.2 & 57 & 74.6 \\
\hline 27 & 77.2 & 58 & 74.5 \\
\hline 28 & 77.1 & 59 & 74.4 \\
\hline 29 & 77.1 & 60 & 74.4 \\
\hline 30 & 77.1 & 61 & 74.4 \\
\hline 31 & 77.2 & 62 & 74.3 \\
\hline 32 & 77.2 & 63 & 74.3 \\
\hline 33 & 77.0 & 64 & 74.3 \\
\hline 34 & 76.9 & 65 & 74.3 \\
\hline 35 & 76.7 & 66 & 74.3 \\
\hline 36 & 76.4 & 67 & 74.3 \\
\hline 37 & 76.2 & 68 & 74.3 \\
\hline 38 & 76.0 & 69 & 74.3 \\
\hline 39 & 75.8 & 70 & 74.2 \\
\hline 40 & 75.7 & 71 & 74.1 \\
\hline 41 & 75.7 & 72 & 74.1 \\
\hline 42 & 75.5 & & \\
\hline
\end{tabular}




\section{Trial \#9}

Table A:17: Trial \#9 Flow Data

\begin{tabular}{ccc}
\multicolumn{3}{c}{ Hydrant } \\
\hline $\begin{array}{c}\text { Time } \\
\text { (min.) }\end{array}$ & $\begin{array}{c}\text { Flow Rate } \\
\text { (cfs) }\end{array}$ & $\begin{array}{c}\text { Volume } \\
\text { (cu. ft. })\end{array}$ \\
\hline 1 & 0.223 & 13.4 \\
2 & 0.668 & 53.5 \\
3 & 0.975 & 112.0 \\
4 & 0.975 & 170.4 \\
5 & 0.975 & 228.9 \\
6 & 0.975 & 287.4 \\
7 & 0.975 & 345.9 \\
8 & 0.975 & 404.4 \\
9 & 0.975 & 462.9 \\
10 & 0.975 & 521.4 \\
\hline
\end{tabular}

\begin{tabular}{ccc}
\multicolumn{3}{c}{ Outflow } \\
\hline $\begin{array}{c}\text { Time } \\
\text { (min.) }\end{array}$ & $\begin{array}{c}\text { Flow Rate } \\
\text { (cfs) }\end{array}$ & $\begin{array}{c}\text { Volume } \\
\text { (cu. ft.) }\end{array}$ \\
\hline 17 & 0 & 0 \\
18 & 0.16 & 4.8 \\
19 & 0.267 & 17.6 \\
22 & 0.414 & 78.9 \\
27 & 0.434 & 206.1 \\
32 & 0.241 & 307.4 \\
37 & 0.134 & 363.6 \\
42 & 0.067 & 393.8 \\
47 & 0.047 & 410.9 \\
52 & 0.032 & 422.7 \\
57 & 0.018 & 430.2 \\
62 & 0.015 & 435.2 \\
79 & 0.007 & 445.1 \\
\hline
\end{tabular}

Figure A.9: Trial \#9

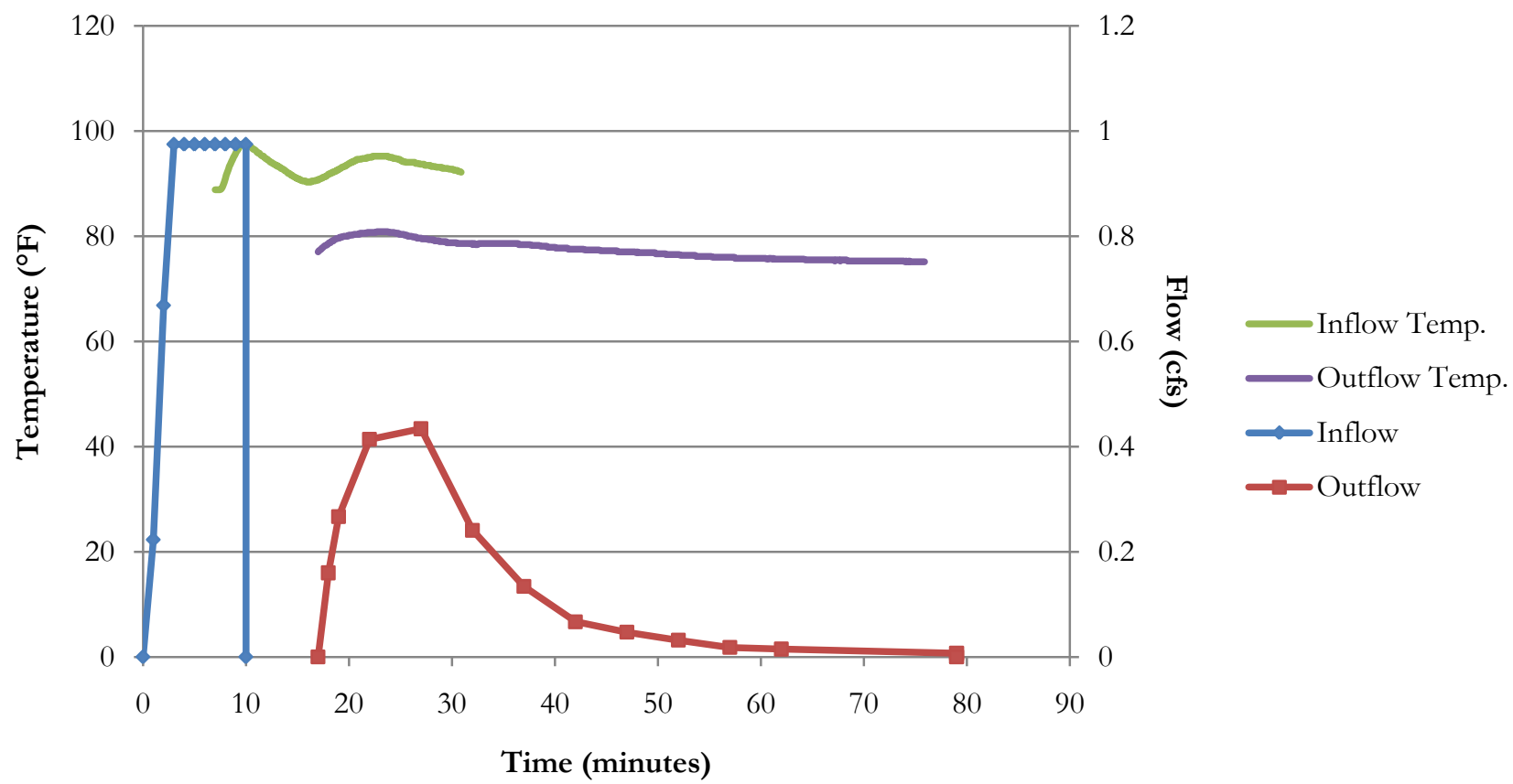

Table A.18: Trial \#9 Temperature Data 
Inflow

\begin{tabular}{cc}
\hline Minute & $\begin{array}{c}\text { Temp. } \\
\left({ }^{\circ} \mathrm{F}\right)\end{array}$ \\
\hline 7 & 89.1 \\
8 & 93.4 \\
9 & 97.0 \\
10 & 97.0 \\
11 & 95.5 \\
12 & 94.1 \\
13 & 92.9 \\
14 & 91.6 \\
15 & 90.6 \\
16 & 90.5 \\
17 & 91.1 \\
18 & 92.2 \\
19 & 93.2 \\
20 & 94.3 \\
21 & 94.8 \\
22 & 95.1 \\
23 & 95.2 \\
24 & 94.8 \\
25 & 94.2 \\
26 & 93.9 \\
27 & 93.6 \\
28 & 93.2 \\
29 & 92.9 \\
30 & 92.5 \\
\hline
\end{tabular}

Outflow

\begin{tabular}{|c|c|c|c|}
\hline Minute & $\begin{array}{c}\text { Temp. } \\
\left({ }^{\circ} \mathrm{F}\right)\end{array}$ & Minute & $\begin{array}{c}\text { Temp. } \\
\left({ }^{\circ} \mathrm{F}\right)\end{array}$ \\
\hline 17 & 77.8 & 47 & 77.0 \\
\hline 18 & 79.2 & 48 & 76.9 \\
\hline 19 & 79.9 & 49 & 76.8 \\
\hline 20 & 80.3 & 50 & 76.7 \\
\hline 21 & 80.6 & 51 & 76.5 \\
\hline 22 & 80.8 & 52 & 76.4 \\
\hline 23 & 80.9 & 53 & 76.3 \\
\hline 24 & 80.6 & 54 & 76.2 \\
\hline 25 & 80.2 & 55 & 76.1 \\
\hline 26 & 79.8 & 56 & 76.0 \\
\hline 27 & 79.5 & 57 & 75.9 \\
\hline 28 & 79.2 & 58 & 75.8 \\
\hline 29 & 78.9 & 59 & 75.8 \\
\hline 30 & 78.7 & 60 & 75.8 \\
\hline 31 & 78.6 & 61 & 75.7 \\
\hline 32 & 78.6 & 62 & 75.7 \\
\hline 33 & 78.6 & 63 & 75.7 \\
\hline 34 & 78.6 & 64 & 75.5 \\
\hline 35 & 78.6 & 65 & 75.5 \\
\hline 36 & 78.5 & 66 & 75.5 \\
\hline 37 & 78.4 & 67 & 75.4 \\
\hline 38 & 78.2 & 68 & 75.4 \\
\hline 39 & 78.0 & 69 & 75.3 \\
\hline 40 & 77.8 & 70 & 75.3 \\
\hline 41 & 77.6 & 71 & 75.3 \\
\hline 42 & 77.6 & 72 & 75.3 \\
\hline 43 & 77.4 & 73 & 75.3 \\
\hline 44 & 77.3 & 74 & 75.2 \\
\hline 45 & 77.2 & 75 & 75.1 \\
\hline 46 & 77.1 & & \\
\hline
\end{tabular}




\section{Trial \#10}

Table A.19: Trial \#10 Flow Data

\begin{tabular}{ccc}
\multicolumn{3}{c}{ Hydrant } \\
\hline $\begin{array}{c}\text { Time } \\
\text { (min.) }\end{array}$ & $\begin{array}{c}\text { Flow Rate } \\
\text { (cfs) }\end{array}$ & $\begin{array}{c}\text { Volume } \\
\text { (cu. ft. })\end{array}$ \\
\hline 1 & 0.111 & 6.7 \\
2 & 0.334 & 26.7 \\
3 & 0.891 & 80.2 \\
4 & 0.891 & 133.7 \\
5 & 0.891 & 187.2 \\
6 & 0.891 & 240.6 \\
7 & 0.891 & 294.1 \\
8 & 0.891 & 347.6 \\
9 & 0.891 & 401.0 \\
10 & 0.891 & 454.5 \\
\hline
\end{tabular}

\begin{tabular}{ccc}
\multicolumn{3}{c}{ Outflow } \\
\hline $\begin{array}{c}\text { Time } \\
\text { (min.) }\end{array}$ & $\begin{array}{c}\text { Flow Rate } \\
\text { (cfs) }\end{array}$ & $\begin{array}{c}\text { Volume } \\
\text { (cu. ft. })\end{array}$ \\
\hline 15 & 0 & 0 \\
16 & 0.147 & 4.4 \\
17 & 0.247 & 16.2 \\
20 & 0.394 & 73.9 \\
25 & 0.368 & 188.2 \\
30 & 0.227 & 206.1 \\
35 & 0.147 & 217.3 \\
40 & 0.114 & 240.8 \\
45 & 0.053 & 265.8 \\
50 & 0.033 & 278.7 \\
55 & 0.028 & 287.9 \\
60 & 0.017 & 294.6 \\
75 & 0.013 & 308.1 \\
\hline
\end{tabular}

Figure A.10: Trial \#10

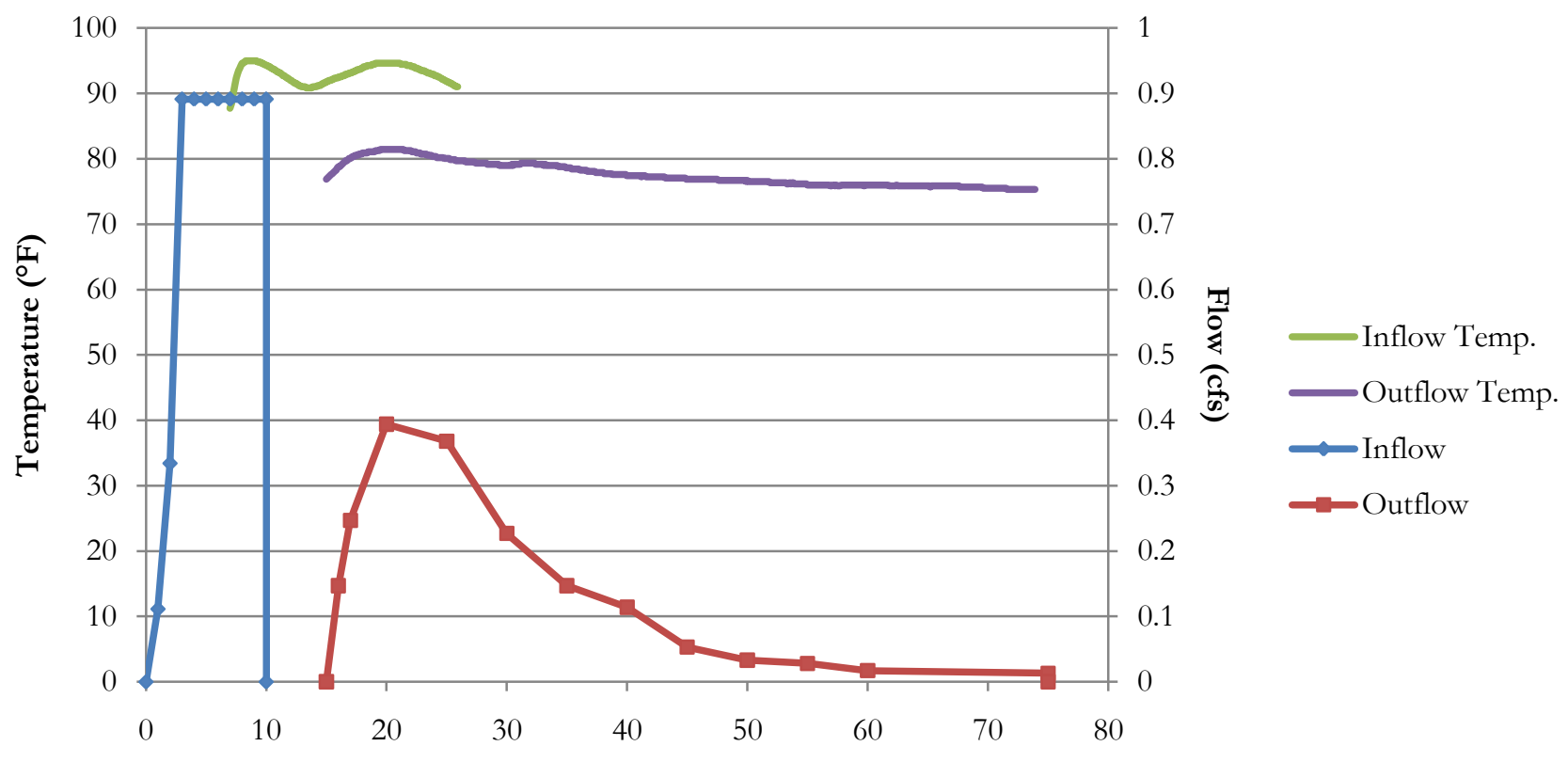

Time (minutes) 
Table A.20: Trial \#10 Temperature Data

\begin{tabular}{cc}
\multicolumn{2}{c}{ Inflow } \\
\hline Minute & $\begin{array}{c}\text { Temp. } \\
\left({ }^{\circ} \mathrm{F}\right)\end{array}$ \\
\hline 7 & 91.5 \\
8 & 94.9 \\
9 & 94.8 \\
10 & 93.9 \\
11 & 92.7 \\
12 & 91.5 \\
13 & 90.9 \\
14 & 91.3 \\
15 & 92.1 \\
16 & 92.8 \\
17 & 93.5 \\
18 & 94.2 \\
19 & 94.6 \\
20 & 94.6 \\
21 & 94.4 \\
22 & 93.9 \\
23 & 93.2 \\
24 & 92.4 \\
25 & 91.4 \\
\hline
\end{tabular}

\begin{tabular}{cccc}
\multicolumn{4}{c}{ Outflow } \\
\hline Minute & $\begin{array}{c}\text { Temp. } \\
\left({ }^{\circ} \mathrm{F}\right)\end{array}$ & Minute & $\begin{array}{c}\text { Temp. } \\
\left({ }^{\circ} \mathrm{F}\right)\end{array}$ \\
\hline 15 & 77.7 & 45 & 76.9 \\
16 & 79.4 & 46 & 76.9 \\
17 & 80.5 & 47 & 76.8 \\
18 & 81.0 & 48 & 76.7 \\
19 & 81.3 & 49 & 76.7 \\
20 & 81.4 & 50 & 76.5 \\
21 & 81.4 & 51 & 76.5 \\
22 & 81.0 & 52 & 76.4 \\
23 & 80.6 & 53 & 76.3 \\
24 & 80.2 & 54 & 76.2 \\
25 & 79.9 & 55 & 76.0 \\
26 & 79.6 & 56 & 76.0 \\
27 & 79.4 & 57 & 75.9 \\
28 & 79.2 & 58 & 76.0 \\
29 & 79.0 & 59 & 76.0 \\
30 & 79.1 & 60 & 76.0 \\
31 & 79.3 & 61 & 76.0 \\
32 & 79.2 & 62 & 75.8 \\
33 & 79.0 & 63 & 75.8 \\
34 & 78.8 & 64 & 75.8 \\
35 & 78.5 & 65 & 75.8 \\
36 & 78.2 & 66 & 75.8 \\
37 & 78.0 & 67 & 75.8 \\
38 & 77.7 & 68 & 75.7 \\
39 & 77.6 & 69 & 75.6 \\
40 & 77.4 & 70 & 75.5 \\
41 & 77.3 & 71 & 75.4 \\
42 & 77.2 & 72 & 75.3 \\
43 & 77.1 & 73 & 75.3 \\
44 & 77.0 & & \\
\hline & & & \\
\hline
\end{tabular}

